\title{
Novel design approach for the analysis of laterally unrestrained reinforced concrete slabs considering membrane action
}

\author{
Journal Article \\ Author(s): \\ Herraiz, Borja; Vogel, Thomas \\ Publication date: \\ 2016-09-15 \\ Permanent link: \\ https://doi.org/10.3929/ethz-a-010674749 \\ Rights / license: \\ In Copyright - Non-Commercial Use Permitted \\ Originally published in: \\ Engineering Structures 123, https://doi.org/10.1016/j.engstruct.2016.05.033
}




\section{$i|b| k$}

Institute of Structural Engineering

Chair of:

Structural Engineering

Structural Design and Conservation
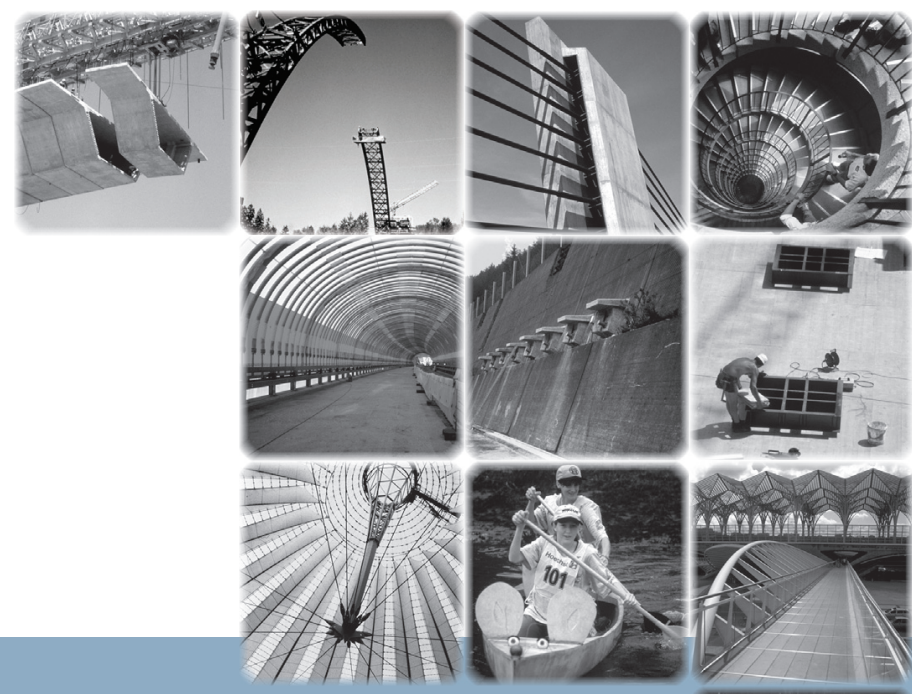

ammira

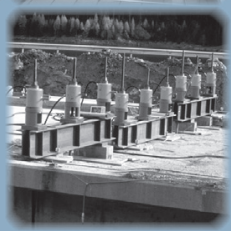

Title:

Novel design approach for the analysis of laterally unrestrained reinforced concrete slabs considering membrane action

Elsevier

Amsterdam, Netherlands

Publication Date

11 June 2016

313

329

English

Modelling; Concrete slabs; Membrane action; Failure criteria; Comparative assessment

Engineering Structures

123

September 2016

Structural Engineering

03353 


\title{
Novel design approach for the analysis of laterally unrestrained reinforced concrete slabs considering membrane action
}

\author{
B. Herraiz *, T. Vogel \\ Institute of Structural Engineering, ETH Zurich, 8093 Zurich, Switzerland \\ *Corresponding author. Email address: herraiz@ibk.baug.ethz.ch
}

\begin{abstract}
In recent years, investigations on the behaviour and modelling of laterally unrestrained reinforced concrete slabs have been intensified due to the reserve of strength that membrane action provides. The existing analytical and numerical design approaches do not lead to satisfactory estimations, especially on failure predictions. In this paper, a novel design approach is described. The behaviour of a slab prior to the development of membrane forces is estimated through classic, renowned methods, and the vertical deflection at which membrane action begins by means of a perfect-plastic kinematic model. For larger deflections, an iterative procedure is proposed to find the distribution of membrane forces that satisfy both, equilibrium, and kinematics of the slab. Two failure criteria are included to determine the maximum load-bearing capacity and deflection. The presented approach, together with other existing design methods, are compared with 43 experimental tests of laterally unrestrained slabs conducted by different authors. The comparison illustrates a good correlation between model prediction and test results, and a clearly improved performance in terms of accuracy and precision is achieved.
\end{abstract}

Keywords: modelling; concrete slabs; membrane action; failure criteria; comparative assessment

\section{Introduction}

Membrane action and maximum capacity estimation of reinforced concrete slabs is a widely researched topic. Most of the investigations conducted so far have focused on the behaviour of laterally restrained slabs at the edges $[1,2,3,4]$ as they require moderate deflections in order to develop compressive membrane action, which greatly enhances their load-bearing capacity. The so-called tensile membrane action, however, requires large deflections to increase the capacity of slabs with and without lateral restraint $[5,6,7]$. Investigations on the large displacement behaviour of laterally unrestrained slabs are scarce due to the absence of effective compressive membrane action.

The phenomenon of tensile membrane action in laterally unrestrained slabs was first noticed by Wood [8]. Further intensive theoretical work, experimental campaigns and development of design approaches $[7,9,10,11,12]$ were performed during the mid-1960s. Research on this topic was abandoned, however, due to the large displacements required to initiate the development of tensile membrane forces in laterally unrestrained slabs, which significantly exceeded the serviceability limits. In recent years, the topic has gained renewed relevance as the reserve of strength that tensile membrane action provides can become relevant in the response of structures under extreme loading conditions. This includes not only fire or blast events, but also progressive collapse scenarios. This reserve of strength can play a key role within the alternative load path strategy for enhancing structural robustness in case of a column removal [13], allowing the slab to redistribute the loads to the remaining supports without collapsing. In all these extreme events, large deflections are usually tolerated as the main objective is to avoid overall structural collapse. In this direction, the investigation of laterally unrestrained slabs at large displacements has become relevant lately, in order to obtain a lower-bound estimate of the load-bearing capacity of slab floors. Several experimental campaigns were performed $[14,15,16,17]$ and new analytical and numerical finite element-based design approaches were developed [18, 19, 20, 21, 22].

All these existing approaches, however, exhibit some drawbacks, making them inaccurate and less suitable for practical purposes. For this reason, a new approach for the assessment of laterally unrestrained reinforced concrete slabs was developed and is introduced hereafter. 


\section{Behaviour of laterally unrestrained reinforced concrete slabs}

Typical specimens subjected to a static monotonically increasing uniform load show a complex behaviour [23]. At low loads, the slab behaves elastically and the uncracked flexural stiffness governs the response. After cracking, moments are redistributed due to the decrease of flexural stiffness at the cracked sections. At larger loads, cracks widen, shifting the neutral axis of the cross section, which causes a lateral expansion of the slab. A complex elastic-plastic mechanism governs the response of the slab at this stage.

The maximum flexural capacity is reached when a collapse mechanism, governed by yield lines, is developed [24], dividing the slab into rigid regions. At this point, deflections increase and the lateral expansion is reduced due to kinematic limitations, until it reverses and the slab begins to contract. Subsequently, the contact surface between the slab segments varies [9] and tensile membrane forces are developed within an internal region of the slab, while a balancing outer compressive ring develops along the supports as it can be seen in Figure 1.

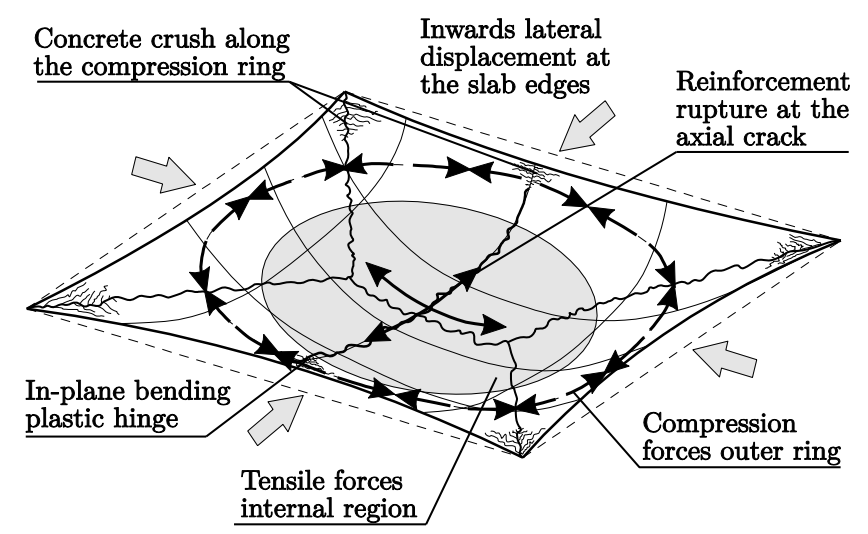

Figure 1. Development of membrane forces in a laterally unrestrained slab at large displacements

The kinematic incompatibility of these inwards lateral displacements with the pre-existing collapse mechanism causes the development of an additional axial crack as reported by different investigations $[7,12,14,17]$. The tensile forces developing along this crack are balanced by the compression forces close to the supports, creating an in-plane bending scissors-like mechanism: the stiff slab segments rotate in-plane about a plastic hinge located in the compressed zone of this axial crack. Several researchers have observed this structural behaviour [12, 20, 21, 22].

These membrane forces increase the load-bearing capacity of the slab by $M-N$ interaction and second order effects. The bending moments produced by the tensile forces in the deflected central region balance the moments created by the vertical loading [10]. The load-bearing capacity of the slab increases with increasing deflections up to failure, which typically occurs along the compression ring due to concrete crushing or reinforcement rupture at the axial crack [14, 16, 17].

\section{Previous research on laterally unrestrained reinforced concrete slabs}

\subsection{Experimental research}

Several small-scale tests were performed during the mid-1960s $[7,9,12]$ in order to study membrane action and the general behaviour of laterally unrestrained slabs. However, most of these investigations lack detailed information and were performed under unclear boundary conditions.

In recent years, additional well-documented experimental campaigns have been carried out following modern methodologies. An initial full-scale test was conducted at the Building Research Establishment (BRE) in 2000 [14], consisting of a single profiled isotropic lightly reinforced rectangular specimen which failed due to a large axial crack formed across the shorter span. Following this investigation, Foster et al. [15] conducted 15 small-scale tests on rectangular specimens in order to assess the effect of orthotropy and reinforcement bond. The majority of these tests show that the maximum load-bearing capacity was reached at relatively low displacements. Hence, it might be 
possible that effective compressive membrane action was developed and consequently the slabs were laterally restrained. In order to further extend the experimental database, Bailey and Toh [16] conducted a campaign with 26 square and rectangular small-scale lightly reinforced specimens tested at ambient temperature. This campaign included slabs with mild and stainless steel as reinforcement, which displayed both crushing of the concrete and reinforcement rupture failure modes. Additionally, Cashell et al. [17] recently conducted another experimental campaign with 18 small-scale lightly reinforced specimens. The main aim of this campaign was to identify the effects of bond strength on membrane action and the observed failure mode.

\subsection{Theoretical research}

Several methods for the characterisation of membrane action in laterally unrestrained slabs were developed during the mid-1960s. Most of these first methodologies were limited to isotropic slabs with just one layer of reinforcement and subjected to a uniformly distributed load.

Wood's [8] approach was restricted to slabs with rotational symmetry. Sawczuk and Winnicki [7] proposed a kinematic and energy-based approach for rectangular slabs with two compatible collapse modes: one including an axial crack across the shorter span of the slab at its mid-point; and another including two axial cracks across the shorter span at the intersection of the yield lines. This method does not fulfil equilibrium and typically leads to overestimations of the capacity. Taylor [9] and Kemp [10] proposed similar methods for square slabs based on the equilibrium of forces. Both methods, however, disregard the development of axial cracks and, therefore, overestimate the strength. Taylor's approach assumes a stationary distribution of forces and the effect of the change in geometry is simply to increase the lever arm of the internal forces. Kemp's approach uses a kinematic model to calculate the distribution of forces considering the $M-N$ interaction, in order to estimate the corresponding strength enhancement for increasing deflections. Morley's [11] method for rectangular slabs is quite similar to that of Sawczuk and Winnicki, but also satisfies the equilibrium of each rigid slab region.

Finally, Hayes [12] proposed an approach for orthotropic rectangular slabs, which is based on equilibrium of the internal membrane forces and in-plane bending moments. He observed that axial cracks develop together with in-plane bending plastic hinges at the compressed zone close to the supports, and considered this effect in his approach. He used a collapse mode including two axial cracks across the shorter span at the intersection of the yield lines as suggested by Sawczuk and Winnicki. This approach assumes a stationary distribution of forces during the deformation process and the capacity of the slab is enhanced for larger deflections due to the increase of the internal lever arm. None of the aforementioned approaches includes failure criteria for the load-deflection relationship, strictly limiting its use to academic purposes.

In the last decade, some new analytical approaches were developed. Bailey and Toh [20] proposed a method that is a slightly modified version of Hayes' one. The difference lies in the assumed collapse mode: a single axial crack is considered across the shorter span of the slab at its mid-point, as observed in most test results. The rest of the procedure is equivalent. This approach, however, introduces the first failure criteria. Bailey and Toh proposed two conservative semi-empirical limits: failure of the reinforcement along the crack and crushing of the concrete at the slab's corners. Finally, Omer et al. [21] proposed an energy-based, bond strength-dependent method similar to the one from Sawczuk and Winnicki. This method ignores equilibrium and the $M-N$ interaction and assumes a collapse mode with an axial crack at its mid-point. The approach originally had only a failure criterion for reinforcement rupture, but Cashell et al. [22] further developed it, introducing a possible concrete crush failure.

Together with these analytical methods, several numerical approaches $[18,19]$ based on advanced shell membrane finite elements were developed. These models, however, often lead to unrealistic stress distributions, as results highly depend on the mesh density. Hence, these models are able to represent the response history of the slab, but they are inadequate to predict failure. Alternatively, the authors have developed a new approach, based on equilibrium and kinematics, which includes well-founded failure criteria and is described in detail hereafter. 


\section{Description of the novel design approach}

\subsection{Scope and adopted assumptions}

The proposed design approach estimates the complete response, including load-bearing capacities, vertical deflections and other kinematic quantities, of laterally unrestrained rectangular reinforced concrete slabs with orthotropic reinforcement in one or two layers under a uniformly distributed load. The slabs can be simply supported or rotationally restrained, but must be vertically supported along all the edges. The structural response is divided into three stages as depicted in Figure 2: a pre-yielding stage, where the flexural stiffness governs the behaviour of the slab; a transitional stage between the pseudo-elastic and pure plastic behaviour of the slab; and a membrane action stage where the enhancement above the flexural ultimate capacity is estimated for every deflection increment until failure is predicted.

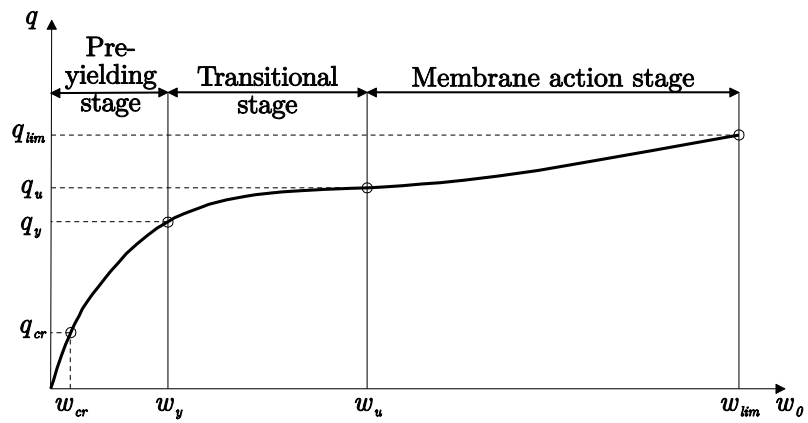

Figure 2. Proposed load-deflection relationship and stages

The assumptions adopted in this design approach are summarised as follows:

- Elastic deformations and displacements are only considered within the pre-yielding stage

- The yield-line collapse pattern does not change for large deflections once membrane forces have developed

- A perfect, rigid-plastic model is used for the kinematic relationships

- The effects of tension stiffening are neglected throughout the approach

- A parabolic-rectangular stress distribution for concrete in compression, as defined in [25], and an elastic-perfect plastic stress-strain relationship for reinforcing steel are used as depicted in Figure 3 a) and b), respectively. Only for the bond-slip relationships described in section 4.4.4, a bi-linear model for reinforcing steel that accounts for strain-hardening is used, as depicted in Figure $3 \mathrm{c}$ ).

a)

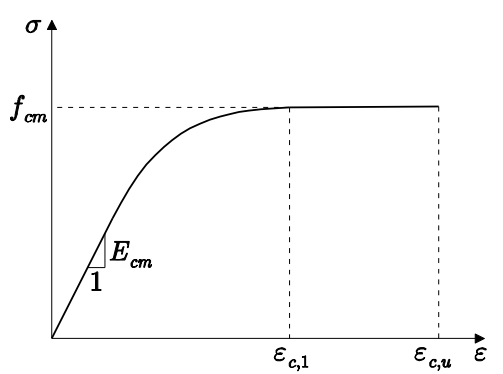

b)

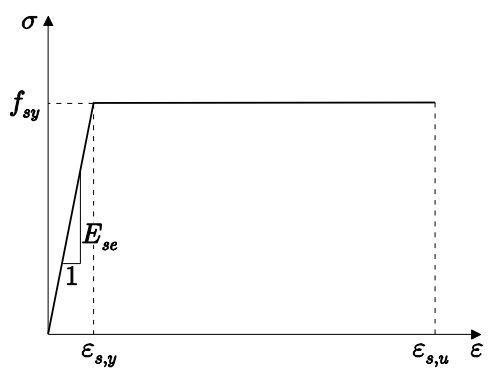

c)

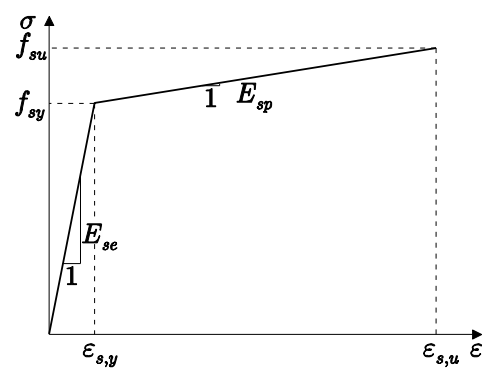

Figure 3. Constitutive material relationships; a) Stress-strain model for concrete in compression; b) General stressstrain model for reinforcing steel in tension and compression; c) Stress-strain model for reinforcing steel in tension for the bond-slip relationships.

\subsection{Pre-yielding stage}

During this first stage, the approach is based on an estimation proposed by Vanderbilt et al. [26]. For low loads up to initial cracking, the deflections are computed based on classic linear elastic premises, using the average uncracked stiffness of the slab. The deflections at the load causing the first yielding 
of the slab are calculated with the average stiffness of the fully-cracked slab, and a parabolic transition between these two points is assumed for deflections at intermediate loads. The proposed approximation is represented in Figure 4.

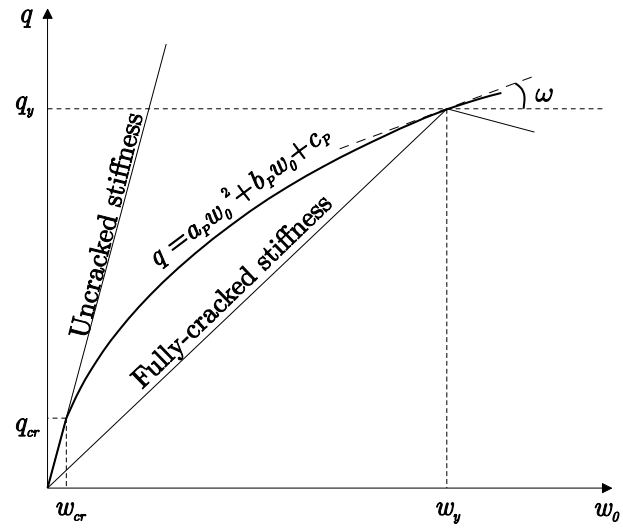

Figure 4. Approximation for the pre-yielding stage, as suggested by Vanderbilt et al. [26].

The solutions for most common boundary conditions and slab geometries of Lagrange's equation, which describes the load-deflection relationship of elastic plates, have been tabulated by several authors [27]. Hence, the four parameters that characterise the linear and parabolic load-deflection relationship of the pre-yielding stage $q_{c r}, q_{y}, w_{c r}$ and $w_{y}$ can be readily computed.

\subsection{Transitional stage}

\subsubsection{Introduction}

Along this stage, complex elastic-plastic interactions occur, which are difficult to model. This short stage, however, does not have a great relevance on the characterisation of the load-deflection relationship. Hence, a detailed calculation of this stage is less important and a mathematical transition curve for the load-deflection relationship is assumed. Two different transition curves are proposed:

- Exponential function $q\left(w_{0}\right)=-e^{-A w_{0}+B}+C$

- Fourth order polynomial function $q\left(w_{0}\right)=A w_{0}{ }^{4}+B w_{o}{ }^{3}+C w_{o}{ }^{2}+D w_{0}+E$

because they lead to unrealistic results out of their application ranges. The exponential function does not lead to acceptable results for slabs with initial low flexural stiffnesses, and the polynomial curve is not suited for slabs with initial high flexural stiffnesses. The parameters characterising the curve are given on the one hand by the final values of the pre-yielding stage $q_{y}$ and $w_{y}$ with the corresponding slope $\omega$ and, on the other hand, by the ultimate flexural load $q_{u}$ given by the yield line-theory with the deflection $w_{u}$ for which membrane forces begin to develop.

The ultimate flexural load and the corresponding yield line mechanism are calculated by applying the rules and assumptions of the classic yield line theory described by Johansen [24]. This load theoretically represents the maximum load-bearing capacity of the slab before membrane forces develop. Hence, this method assumes that the load-deflection relationship asymptotically approaches $q_{u}$ at the end of this stage, meaning that the curve's slope is horizontal at this point.

The vertical deflection $w_{u}$ for which membrane forces begin to develop is assumed to be the point for which the lateral displacements at the supports reverse from expanding to contracting (see section 2). A kinematic model of the slab is used in order to calculate the relationship between the lateral displacements at the supports and the ultimate deflection $w_{u}$ of the slab.

\subsubsection{Critical collapse mechanism and ultimate flexural load}

In order to define the ultimate flexural load $q_{u}$, the correspondent yield line mechanism must be estimated [24]. The estimation of the critical yield line mechanism of a uniformly loaded orthotropic rectangular slab with all edges fixed is a classical problem, which has been described by several authors. 
In Figure 5, this critical yield line mechanism is depicted together with the parameters that define its dimensions and proportions.

Because of the symmetry in geometry, loading and material properties of the slab, the yield line EF lies on the slab's centre line parallel to its longer span and the angles $\alpha$ of all the diagonal positive yield lines with the horizontal axis are the same. Hence, $\psi$ is the only unknown parameter. A comprehensive derivation of the parameter $\psi$ and the yield line mechanism that leads to the minimum compatible collapse load can be found in [23]. Equation (1) describes the parameter $\psi$ in terms of geometry and material characteristics of the slab:

$$
\psi=\frac{1}{2 \gamma^{2} \eta} \frac{X}{Y}\left(\sqrt{\left(\frac{X}{Y}\right)^{2}+3 \eta \gamma^{2}}-\frac{X}{Y}\right)
$$

where $\gamma$ is the aspect ratio of the slab $(L / l)$ and $\eta$ is the coefficient of orthotropy, which denominates the ratio of the positive ultimate moment capacity of the slab for both orthogonal directions $\left(m_{u, 0, y} / m_{u, 0, x}\right)$ as defined in Figure 5. For a square slab with isotropic or orthotropic reinforcement, the shorter span $l$ of the slab is set as the span with the lower ultimate moment $\left(m_{u, 0, x}\right)$ so that the coefficient of orthotropy $\eta$ is larger than, or equal to unity. The purpose of this assumption is that Equation (1) always yields to values of $\psi$ less than, or equal to 0.5 , describing a valid yield line mechanism.

The $X$ and $Y$ parameters define the ratio between the negative and positive ultimate moment capacity of the slabs for each $x$ and $y$ orthogonal direction, respectively. These parameters are described by the following expressions:

$$
X=2\left(\sqrt{1+\frac{m_{u, 0, x}^{\prime}}{m_{u, 0, x}}}\right) \quad Y=2\left(\sqrt{1+\frac{m_{u, 0, y}^{\prime}}{m_{u, 0, y}}}\right)
$$

Hence, the ultimate load of a uniformly loaded orthotropic rectangular slab with fixed edges can be expressed with the following terms [23]:

$$
q_{u}=\frac{6 m_{u, 0, y} Y^{2}}{l^{2}(3-4 \psi)}
$$

If the slab is simply supported, Equations (1) and (3) and the corresponding collapse mechanism described by Figure 5 are still valid, given that $m_{u, 0, x^{\prime}}$ and $m_{u, 0, y^{\prime}}$ are zero and therefore $X=Y=2$.

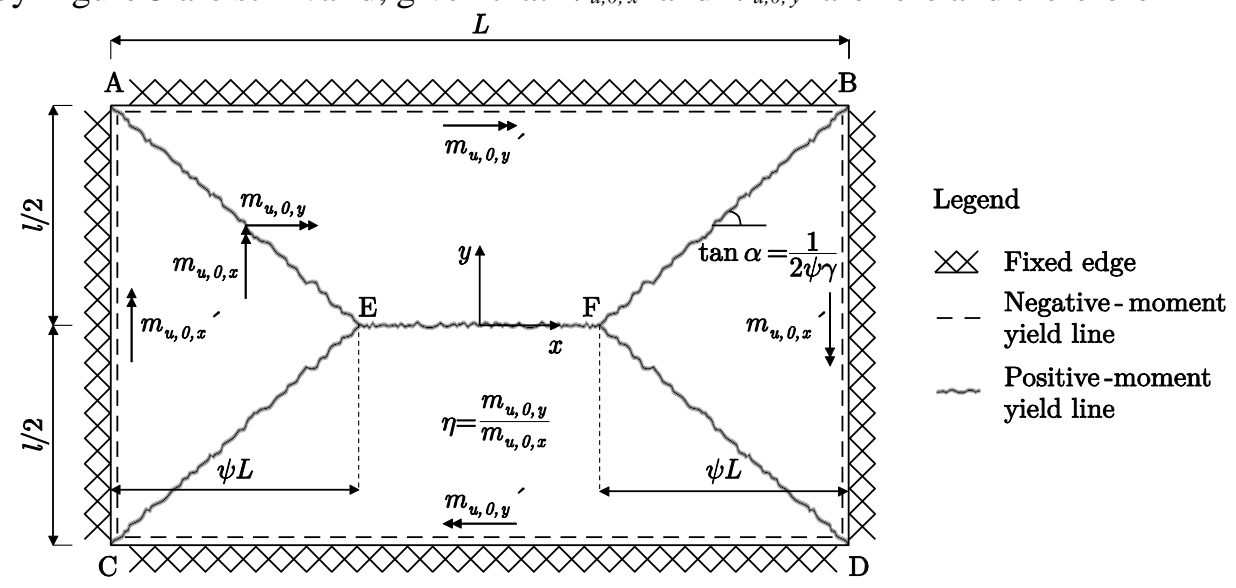

Figure 5. Critical yield line mechanism of a uniformly loaded orthotropic rectangular slab with fixed edges.

\subsubsection{Description of the kinematic model}

The assumed kinematic model consists of perfect plastic yield lines and non-deformable slab regions. An axial mid-crack across the shorter span is also included in the kinematic model, allowing horizontal displacements. Furthermore, the position of the neutral axis of the cross-section is assumed to be equal on both sides of the yield line, leading to fixed averaged concrete depths for the ultimate pure positive and negative bending moments, $c_{n}$ and $c_{n}{ }^{\prime}$, respectively. It is important to note the difference between 
the neutral axis for pure bending $(n=0)$ and the neutral axis once membrane forces develop $(n \neq 0)$. The parameter $\mu(y)$ describes the variation of concrete depth with respect to the neutral axis for pure bending along the yield line. Based on these assumptions, the kinematic model is depicted in Figure 6.

The parameter $d_{c c}$ describes the position of the axis of rotation along the edges of the slab. For simply supported slabs, $d_{c c}=h / 2$, the slab rotates about the axis of the slab's mid-plane; for rotationally restrained slabs, $d_{c c}=0.4 c_{n}^{\prime}$, the slab rotates about an axis at the centre of the compression zone.

Given a vertical deflection at the centre of the slab $w_{0}$, the corresponding rotations of the triangular and trapezoidal slab regions relative to the horizontal plane for the $x$ - and $y$-direction are $\theta$ and $\varphi$, respectively. These rotations are assumed to be small. The lateral displacements $u(y)$ of the slab at the axis of rotation in the $x$-direction, the lateral displacements $s(y)$ along the axial crack and the partial elongations $e_{x}(y)$ in the $x$-direction at the neutral axis of the yield lines, are also assumed to be negligible in comparison with the slab dimensions. According to Figure 6, the following relationships between the rotations $\theta$ and $\varphi$, as well as the central vertical deflection $w_{0}$ are proposed:

$$
w_{o}=\frac{l}{2} \varphi \quad w_{o}=\psi L \theta
$$

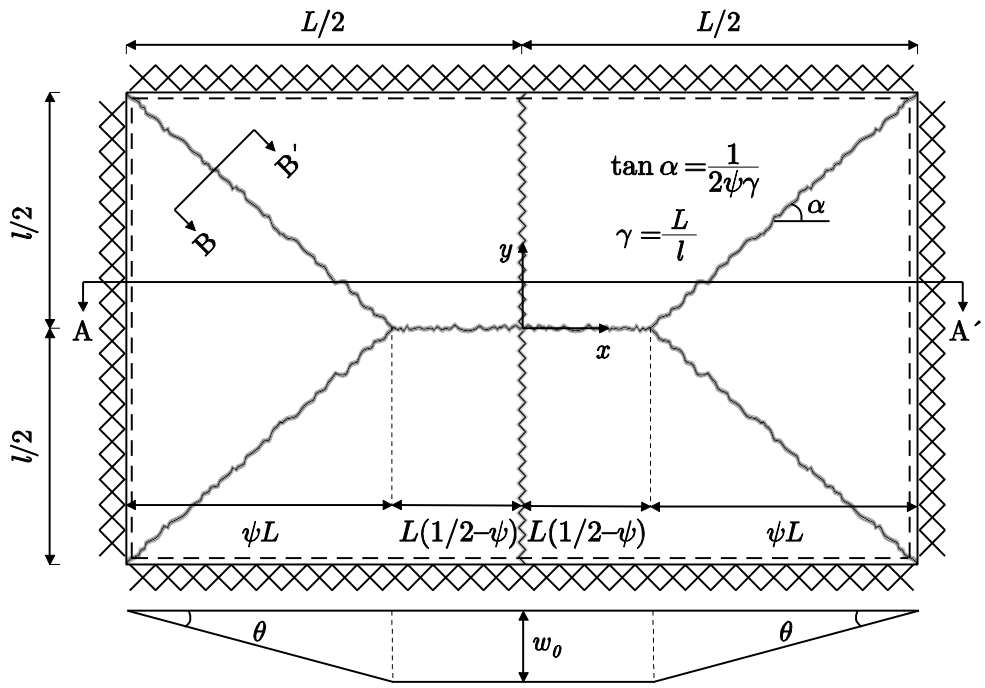

Section A-A'

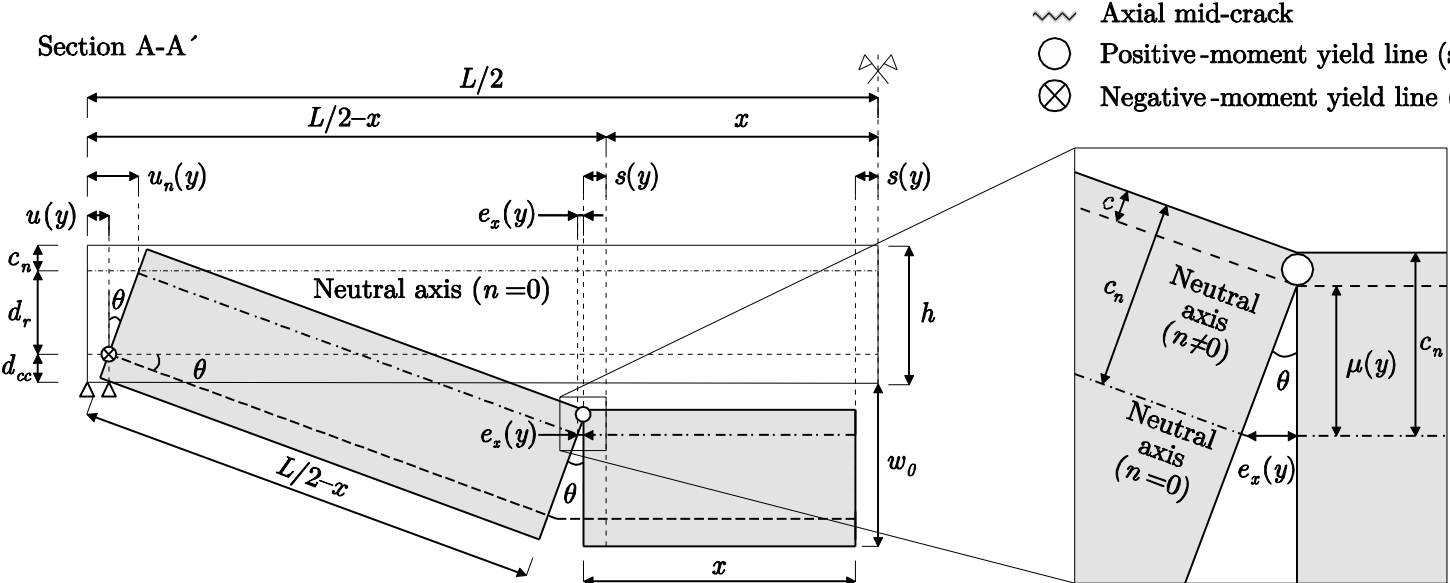

Figure 6. Rigid, perfectly-plastic slab model. Kinematic relationships of the deformed slab along the $x$-direction (Section A-A') and orthogonal to the diagonal yield lines (Section B-B').

Hence, the ratio between the slab's rotations for both orthogonal directions, denoted by $\Lambda$, is:

$$
\frac{\theta}{\varphi}=\frac{l}{2 \psi L}=\frac{1}{2 \psi \gamma}=\frac{1}{\Lambda}
$$

leading to the following relationship between the coordinates along the diagonal yield lines: 


$$
x=L\left(\frac{1}{2}-\psi\right)+\Lambda y \quad \text { for } 0 \leq y \leq \frac{l}{2}
$$

Considering Section A-A' from Figure 6, the lateral displacement of the slab in the $x$-direction at the neutral axis for pure bending is $u_{n}(y)$, and choosing this axis as the reference, $e_{x}(y)$ can be estimated through the following kinematic relationship:

$$
\frac{L}{2}-x=u_{n}(y)+\left(\frac{L}{2}-x\right) \frac{\theta^{2}}{2}+e_{x}(y)+s(y)
$$

Further geometric relationships between $u_{n}(y)$ and $u(y)$ as well as $\mu(y)$ and $e_{x}(y)$ are given by:

$$
u_{n}(y)=u(y)+d_{r} \theta \quad e_{x}(y)=\mu(y) \theta
$$

Considering Equations (8) and (6), Equation (7) can be rewritten as:

$$
(L \psi-\Lambda y) \frac{\theta^{2}}{2}=u(y)+d_{r} \theta+\mu(y) \theta+s(y)
$$

In order to solve this equation, a relationship between $s(y)$ and $u(y)$ is required. Both parameters are defined as pure horizontal translations and are independent of cross-sectional rotations. Hence, this relationship can be obtained by means of the geometric and kinematical relations of the rigid slab regions on the horizontal plane at the axis of rotation. The designated rotations $\theta^{\prime}$ and $\varphi^{\prime}$, and the parameter $\mu(y)$ can be obtained by considering the relationships between the partial elongation of the yield lines for each of the triangular and trapezoidal segments $e_{\theta}{ }^{\prime}$ and $e_{\varphi}{ }^{\prime}$, respectively, according to Section B-B' from Figure 6:

$$
\theta^{\prime}=\frac{e_{\theta}^{\prime}}{\mu(y)} \quad \varphi^{\prime}=\frac{e_{\varphi}^{\prime}}{\mu(y)} \quad \frac{e_{\theta}^{\prime}}{e_{\varphi}^{\prime}}=\frac{\theta^{\prime}}{\varphi^{\prime}}
$$

Following the geometrical derivation described in Figure 7 a), it can be shown that the ratio between $\theta$ and $\varphi$, described by Equation (5), is related to the ratio of $\theta^{\prime}$ to $\varphi^{\prime}$ :

$$
\frac{\theta^{\prime}}{\varphi^{\prime}}=\frac{\tan \alpha}{2 \psi \gamma}=\frac{1}{(2 \psi \gamma)^{2}}=\frac{1}{\Lambda^{2}}=\left(\frac{\theta}{\varphi}\right)^{2}
$$

With the assumption of perfect rigid-plastic behaviour and allowing only rigid body translations and rotations, a straight line always describes the contact between the slab segments along the yield lines as illustrated in Figure $7 \mathrm{~b}$ ). Hence, the parameter $\mu(y)$ varies linearly along the yield lines, independently of the deformation state of the slab defined by two unknowns, namely $\mu(0)$ and $y_{0}$ :

$$
\mu(y)=\mu(0)\left(1-\frac{y}{y_{0}}\right)
$$

In the same direction, the angles on the horizontal plane at the axis of rotation $\beta$ and $\beta^{\prime}$, follow the same ratio as the angles $\theta^{\prime}$ and $\varphi^{\prime}$, as can also be derived from Figure $7 \mathrm{~b}$ ) and Equation (10). A relationship between $u(y)$ and $s(y)$ can be found by expanding these relationships to the edges of the slab as well as considering that all the rotations are small and that $u(y), s(y)$ and $e_{x}(y)$ are negligible compared to the slab dimensions. Taking into account the kinematic compatibility of the rigid slab segments, considering Equation (11) and neglecting second-order displacements, this relationship can be estimated as:

$$
\frac{s(y)}{\beta^{\prime}}=\frac{u(y)}{\beta} \rightarrow s(y)=\frac{\beta^{\prime}}{\beta} u(y)=\frac{\varphi^{\prime}}{\theta^{\prime}} u(y)=\Lambda^{2} u(y)
$$

Referring back to Equation (9) and considering Equation (12) and (13), a new expression for the kinematic relationships in the $x$-direction, independent of $s(y)$, is obtained: 


$$
u(y)=\frac{1}{\left(1+\Lambda^{2}\right)}\left[(L \psi-\Lambda y) \frac{\theta^{2}}{2}-d_{r} \theta-\mu(0)\left(1-\frac{y}{y_{0}}\right) \theta\right]
$$

a)

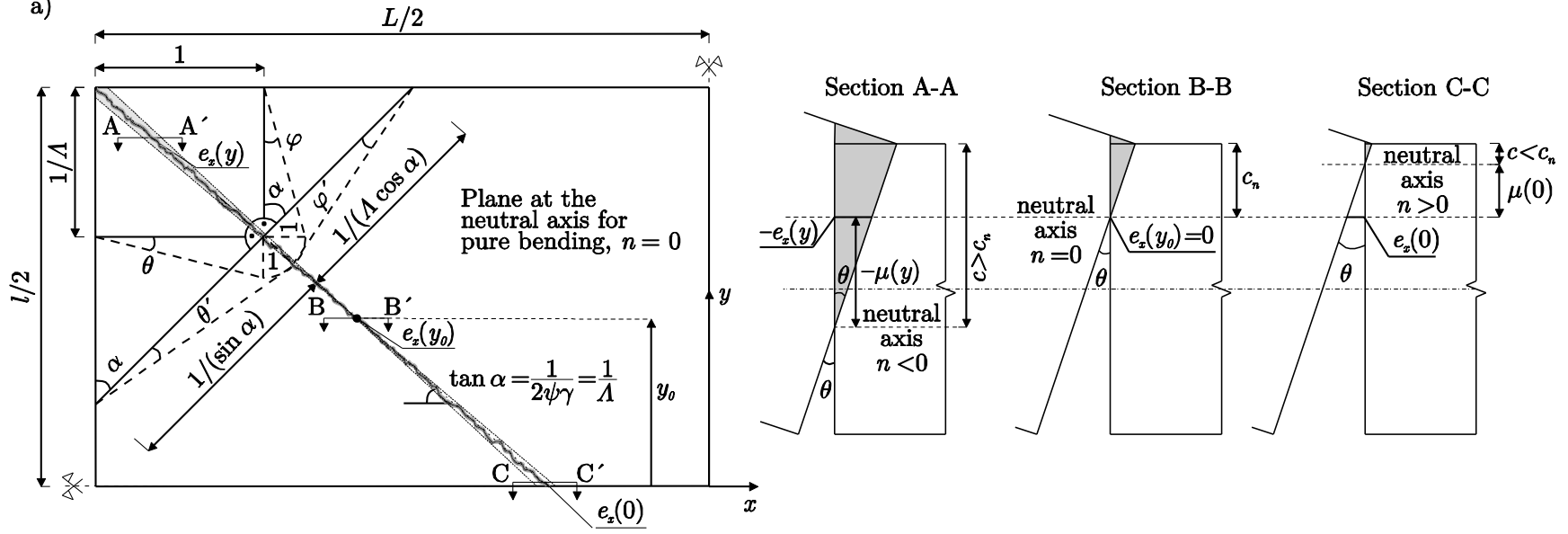

b)

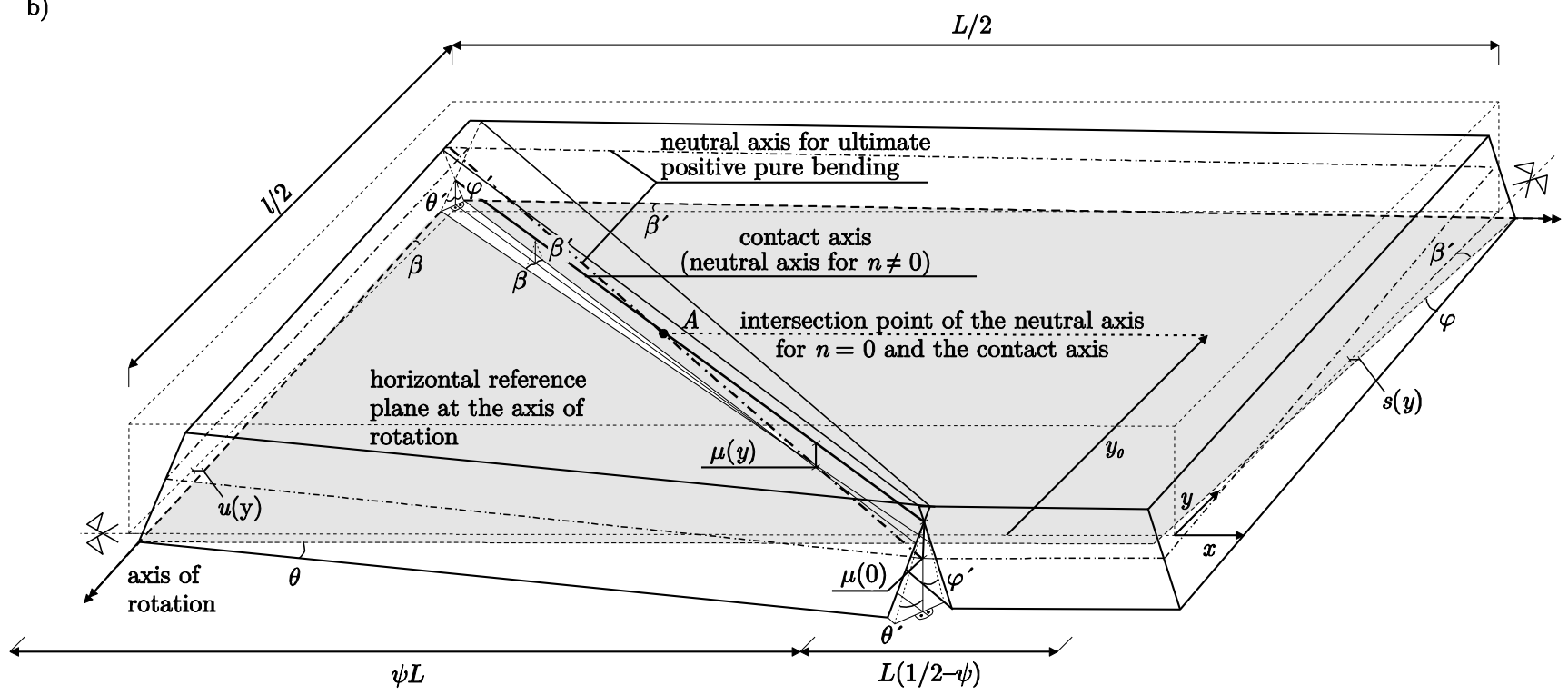

Figure 7. a) Rotational relationships for different angles $\left(\theta, \varphi, \theta^{\prime}\right.$ and $\left.\varphi^{\prime}\right)$ and kinematic relationships along the diagonal yield lines between the neutral axis $n \neq 0$ and the neutral axis $n=0$; b) Geometric relationships for the intersection of the deflected slab with the horizontal plane at the axis of rotation including the lateral displacements

The lateral displacements of the slab's edges for both orthogonal directions are related. From Equation (14) and based on the geometrical relationships shown in Figure $7 \mathrm{~b}$ ), the lateral displacements $v(x)$ of the slab can be described at the axis of rotation in the $y$-direction with the following expression:

$$
v(x)=\frac{\Lambda}{\left(1+\Lambda^{2}\right)}\left[\left(\gamma \frac{l}{2}-x\right) \frac{\varphi^{2}}{2}-\Lambda d_{r} \varphi-\mu(0) \varphi\left(\Lambda-\frac{l}{2 y_{0}}\left(\frac{2 x}{l}+\Lambda-\gamma\right)\right)\right]
$$

\subsubsection{Estimation of the ultimate vertical deflection $w_{u}$}

Before membrane forces develop, the contact line between the slab segments is assumed to be equal to the neutral axis of the ultimate moment for pure bending. This condition is implemented in the kinematic relationships by assuming $\mu(0)=0$ in Equations (14) and (15). Hence, in order to estimate the ultimate vertical deflection $w_{u}$, these equations are evaluated for $\mu(0)=0$ within the transitional stage.

The reversal of the lateral displacements of the edges, $u(y)$ and $v(x)$, corresponds to a $w_{0}$ for which the slope of the describing function is horizontal. Applying this condition to Equations (14) and (15), evaluated for $\mu(0)=0$, leads to Equation (16): 


$$
\begin{aligned}
& \frac{d(u(y))}{d \theta}=\frac{1}{\left(1+\Lambda^{2}\right)}\left((L \psi-\Lambda y) \theta-d_{r}\right)=0 \\
& \frac{d(v(x))}{d \varphi}=\frac{\Lambda}{\left(1+\Lambda^{2}\right)}\left(\left(\gamma \frac{l}{2}-x\right) \varphi-\Lambda d_{r}\right)=0
\end{aligned}
$$

Rearranging these equations, and considering the relationships in Equation (4) leads to:

$$
w_{u, \text { short }}(y)=\frac{d_{r} L \psi}{L \psi-\Lambda y} \quad w_{u, \text { long }}(x)=\frac{l}{2} \frac{\Lambda d_{r}}{\gamma \frac{l}{2}-x}
$$

$w_{u}$ therefore depends on the chosen reference point along the considered edge. This approach assumes that, once at least one point of each edge starts moving inwards, the correspondent edge begins to contract. For both cases, this point corresponds to the midpoint of the edge. Replacing the variables of Equation (17) of the shorter and longer edge with $y=0$ and $x=0$, respectively, leads to the following expressions:

$$
w_{u, \text { short }}=d_{r} \quad w_{u, \text { long }}=2 \psi d_{r}
$$

Hence, $w_{u}$ is, in general, different for the shorter and longer edges, meaning that for a specific $w_{0}$, one of the edges begins to contract while the other is still expanding. This design approach assumes that membrane action starts for a deflection for which all the edges of the slab move inwards, and $w_{\mathrm{u}}$ therefore corresponds to the largest of the obtained ultimate vertical deflections. Comparing the values of Equation (18) and taking into account that the parameter $\psi$ cannot exceed 0.5, the ultimate vertical deflection of the mid-point of the slab is:

$$
w_{u}=d_{r}
$$

In this approach, membrane forces are therefore assumed to start developing for vertical deflections larger than the lever arm of the averaged neutral axis for the ultimate positive pure bending moment.

4.4 Membrane action stage

\subsubsection{Introduction}

In this final stage, the distribution of membrane forces is estimated for each deflection by means of the previously described kinematic model and additional equilibrium relationships until failure occurs. For this purpose, an iterative procedure is required:

- Firstly, given a specific deflection $w_{0}$ larger than $w_{u}$, an initial distribution of concrete depths $c(y)$ along the yield lines of the slab is chosen, which simultaneously defines the membrane forces and bending moments distribution along the yield lines.

- Secondly, the relative lateral displacements along the axial crack are calculated by means of the previously described kinematic model.

- Subsequently, the strains along this crack and their corresponding forces are estimated by means of bond-slip and material models.

- Finally, once the membrane forces along the axial crack and the yield lines are known, in-plane equilibrium of forces and in-plane equilibrium of bending moments about the compressed zone of the mid-crack are calculated.

In general, equilibrium is not satisfied after this last step, and new distributions of concrete depths along the yield lines of the slab must be chosen iteratively, until the specific distribution that satisfies both kinematics and equilibrium is obtained. Once this distribution is found, the corresponding load- bearing capacity of the slab can be estimated. 
The procedure continues for increasing deflections until failure occurs. The proposed design approach considers two possible failures, namely, concrete crushing along the compression ring and reinforcement rupture at the mid-crack.

The individual steps of this procedure are thoroughly described in the following paragraphs.

\subsubsection{Distribution of concrete depths and ultimate internal forces along the yield lines}

The distribution of concrete depths $c(y)$ along the diagonal yield lines can be expressed in terms of $c_{n}$ and the parameter $\mu(y)$. Based on the relationships depicted in Figure 7 a) and Equation (12), the following linear relationship is obtained:

$$
c(y)=c_{n}-\mu(0)\left(1-\frac{y}{y_{0}}\right)
$$

Furthermore, the distribution of concrete depths along the yield line parallel to the longer span of the slab is assumed to follow the same linear distribution as the diagonal yield line. Considering the kinematic relationships of Figure 7 and Equation (6) leads to the following distribution:

$$
c(x)=c_{n}-\mu(0)+\frac{\mu(0)}{\Lambda y_{0}}\left[x-L\left(\frac{1}{2}-\psi\right)\right]
$$

Once the concrete depths along the yield lines are defined, it is possible to calculate the corresponding internal forces of the cross sections. A modification of Johansen's yield criterion [24] which accounts for $M-N$ interaction is used for this approach. Assuming that all cross sections along the yield lines are at their ultimate capacity and considering reinforcement rupture and concrete crush failures, it is possible to determine two possible ultimate curvatures, described by Equation (22), by means of the cross section geometry as can be derived from Figure 8 a).

$$
\chi_{A}=\frac{\varepsilon_{s, u}}{d-c} \quad \chi_{B}=\frac{\varepsilon_{c, u}}{c}
$$

Leading to a transitional concrete depth between the two possible failure criteria, $c_{A B}$, by equating $\chi_{\mathrm{A}}=\chi_{\mathrm{B}}$ :

$$
c_{A B}=d \frac{\varepsilon_{s, u}}{\varepsilon_{s, u}+\varepsilon_{\mathrm{c}, u}}
$$

Concrete depths smaller than $c_{A B}$, for which $\chi_{\mathrm{A}}$ is the ultimate curvature, lead to reinforcement rupture. Concrete depths larger than $c_{A B}$, for which $\chi_{B}$ is the ultimate curvature, lead to concrete crushing. Each concrete depth is therefore associated with a specific ultimate curvature. Both parameters completely define the strain and, by means of the material models, tensional state of a cross section at ultimate capacity and the correspondent ultimate internal forces. For all the possible concrete depths $c$, a single value $c_{n}$, applies for the ultimate moment for pure bending. All other depths lead to bending-tensile or bending-compression states, which correspond to the membrane action stage $(\mu(0) \neq 0)$ as it can be seen

a) in Figure 8 b).

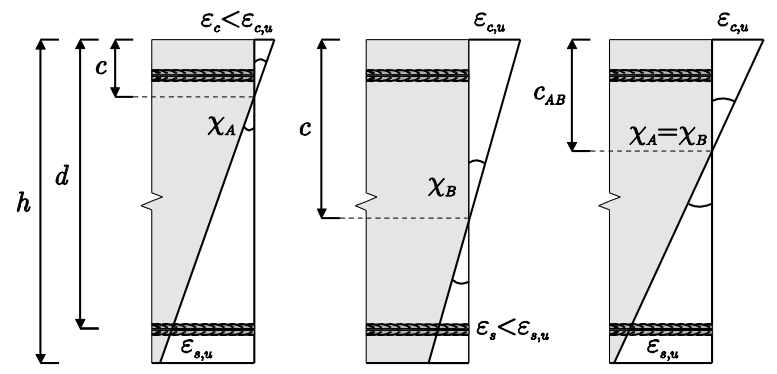

b)

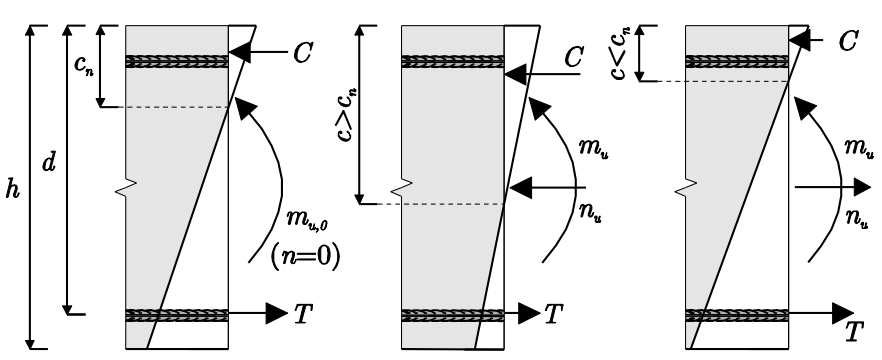

Figure 8. a) Ultimate curvatures $\chi_{\mathrm{A}}$ and $\chi_{\mathrm{B}}$, and transition concrete depth $c_{A B} ; \mathrm{b}$ ) Internal forces for the ultimate capacity as a result of different concrete depths 
Hence, the distribution of concrete depths along the yield lines of the slab and the corresponding ultimate internal cross section forces depend only on two parameters, $\mu(0)$ and $y_{0}$.

\subsubsection{Relative lateral displacements along the axial crack}

Based on the previous distribution of concrete depths along the yield lines, the lateral relative displacements along the axial crack once membrane forces are developed, are estimated. For this purpose, the following derivation is proposed:

Firstly, the total lateral displacements along the axial crack are calculated for the membrane action stage. Assuming that Equation Error! Reference source not found. holds for the membrane action stage and combining it with Equation (14), the following distribution is obtained:

$$
s(y)=\frac{\Lambda^{2}}{\left(1+\Lambda^{2}\right)}\left[(L \psi-\Lambda y) \frac{\theta^{2}}{2}-d_{r} \theta-\mu(0)\left(1-\frac{y}{y_{0}}\right) \theta\right]
$$

This equation represents the total lateral displacements along the axial crack. The crack does not exist, however, before membrane forces start developing and only forms once these total lateral displacements reverse from expanding to contracting. A different vertical deflection is required to produce this reversal along each point of the crack's length, which is calculated by setting the slope of the describing function to zero:

$$
\frac{d(s(y))}{d \theta}=\frac{\Lambda^{2}}{\left(1+\Lambda^{2}\right)}\left[(L \psi-\Lambda y) \theta-d_{r}-\mu(0)\left(1-\frac{y}{y_{0}}\right)\right]=0
$$

Rearranging this equation, the required deflections at which a specific point of the crack starts opening (Equation (26)) and the point at which the displacements reverse (Equation (27)), are obtained:

$$
\begin{gathered}
w_{i n i}=\frac{L \psi\left[d_{r}+\mu(0)\left(1-\frac{y}{y_{0}}\right)\right]}{L \psi-\Lambda y} \\
y_{c r}=\frac{L \psi \theta-d_{r}-\mu(0)}{\Lambda \theta-\frac{\mu(0)}{y_{0}}}
\end{gathered}
$$

This last equation describes the length of the tensile zone of the crack for a specific deflection which is used later for the equilibrium relationships. Evaluating Equation (24) for the deflections given by Equation (26), the initial lateral displacements distribution before membrane forces develop is obtained:

$$
s_{i n i}(y)=-\frac{\Lambda^{2}}{2\left(1+\Lambda^{2}\right)} \frac{\left[d_{r}+\mu(0)\left(1-\frac{y}{y_{0}}\right)\right]^{2}}{L \psi-\Lambda y}
$$

Finally, by subtracting $s_{\text {ini }}(y)$ from $s(y)$, the distribution of relative lateral displacements $s_{\mathrm{r}}(y)$ can be determined:

$$
\begin{aligned}
s_{r}(y)= & s(y)-s_{i n i}(y)=\frac{\Lambda^{2}}{\left(1+\Lambda^{2}\right)}\left[(L \psi-\Lambda y) \frac{\theta^{2}}{2}-d_{r} \theta\right. \\
& \left.-\mu(0)\left(1-\frac{y}{y_{0}}\right) \theta+\frac{\left(d_{r}+\mu(0)\left(1-\frac{y}{y_{0}}\right)\right)^{2}}{2(L \psi-\Lambda y)}\right]
\end{aligned}
$$

Hence, the relative lateral displacements of the crack during the membrane action stage are obtained by applying Equation (29) along the tensile zone range, $0 \leq y \leq y_{c r}$, of the axial crack. 


\subsubsection{Bond-slip model}

Based on these axial crack relative lateral displacements, the strains and corresponding distribution of tensile forces in this region can be estimated by means of a strain-displacement relationship. This relationship is assumed to be described by means of a modified bond-slip model for a pull-out test. The effect at the axial crack opening is similar to a pull-out of a reinforcing bar (see Figure 9). In this case, the pulling force arises by the compatibility disjoining movement of the opposite slab segment, producing a slip between concrete and reinforcement.

This approach assumes that the rebar is completely embedded in the concrete before membrane forces develop. If the slip due to intermediate transversal cracks is neglected, this axial crack slip is equal to the relative displacement $s_{r}(y)$ along the crack.

\begin{tabular}{lcc} 
& Poor bonding conditions & Good bonding conditions \\
\cline { 2 - 3 } Regular ribbed bars & $\tau_{b}=3.85\left(\frac{f_{c m}}{25}\right)^{0.25}$ & $\tau_{b}=5.6\left(\frac{f_{c m}}{25}\right)^{0.25}$ \\
Plain cold drawn wire & $\tau_{b}=0.05\left(\sqrt{f_{c m}}\right)$ & $\tau_{b}=0.1\left(\sqrt{f_{c m}}\right)$ \\
Plain hot rolled bars & $\tau_{b}=0.15\left(\sqrt{f_{c m}}\right)$ & $\tau_{b}=0.3\left(\sqrt{f_{c m}}\right)$ \\
\hline
\end{tabular}

Table 1. Assumed bond strengths for different kinds of rebar and bond conditions [25]

In order to characterize the global behaviour, a local bond-slip model is required. The model suggested by the fib Model Code [25] is modified, taking into account that the bond between concrete and steel is damaged due to the large deformations that the slab experience prior to the development of membrane forces. A perfect-plastic bond-slip relationship with a bond strength equal to the mid-value of the maximum and the residual bond strength is chosen as depicted in Figure $10 \mathrm{a}$ ). Splitting of concrete is also considered, as it is the most common failure for pull-out tests in specimens with realistic concrete covers and confinement conditions. Based on these assumptions, the considered bond strengths for different kinds of rebar are described in Table 1.

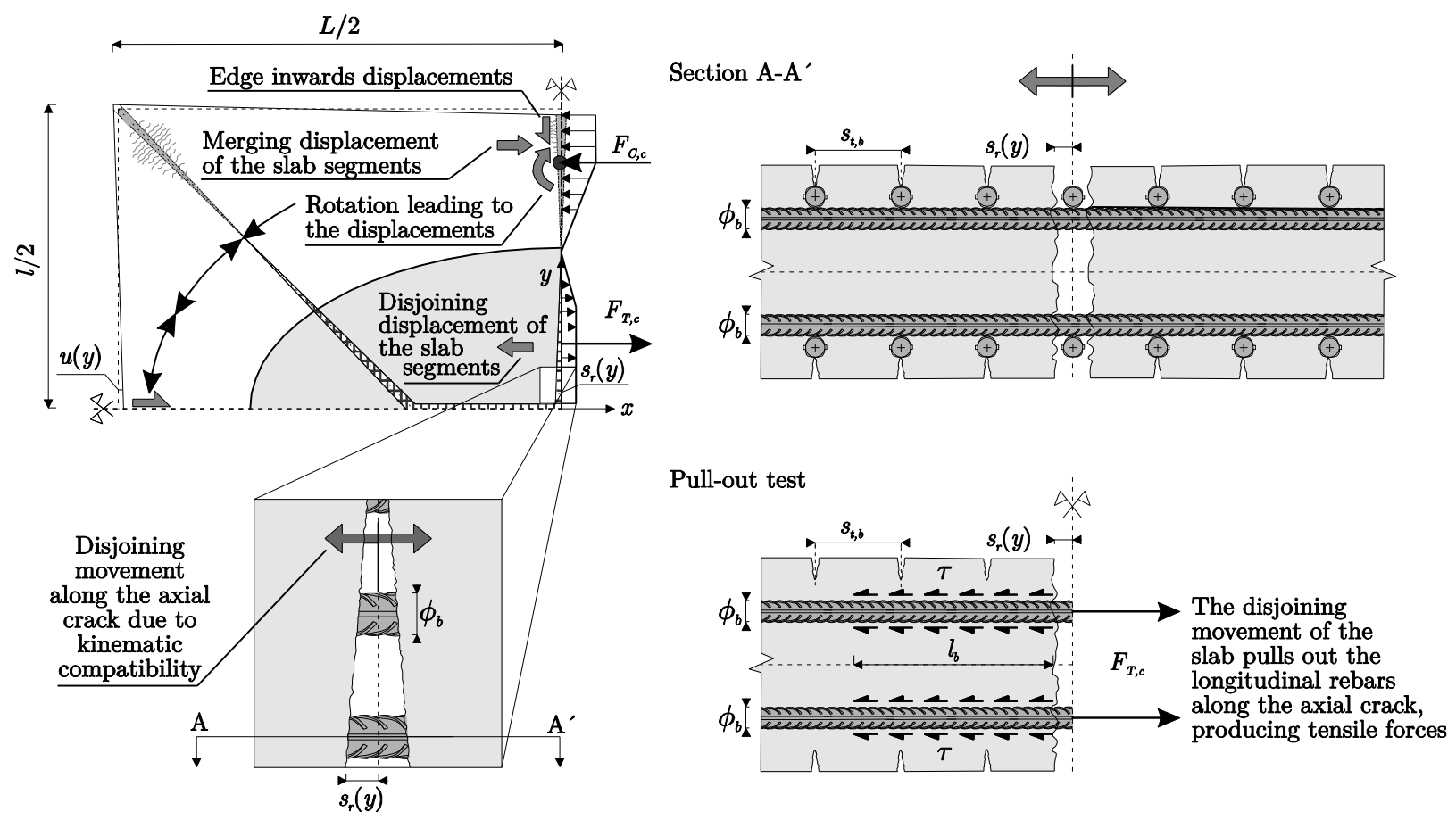

Figure 9. Comparison between a rebar pull-out and the disjoining movement along the axial crack of the slab 
These local bond strengths are modified as suggested in [25], in order to consider the influence of different effects on the bond properties. The influence of transverse cracking is implemented by means of the factor $\lambda$, assuming that the cracks occur with the same spacing as the transverse reinforcing bars, as they normally develop at these locations. An average value of the bond strength, $\tau_{b, m}$, across the entire bonding length, $l_{b}$, is used to implement transverse cracking as depicted in Figure $10 \mathrm{~b}$ ). Furthermore, the effect of yielding is introduced by means of the factor $\Omega_{y}$. Similar to the effect of transverse cracking, an additional mean value of the bond strength $\tau_{b, y}$ for the yielded bonding length $l_{b, y}$ is employed.

a)

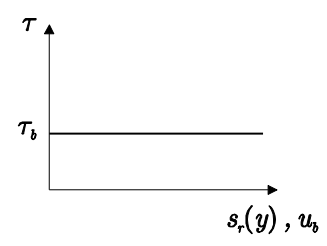

b)

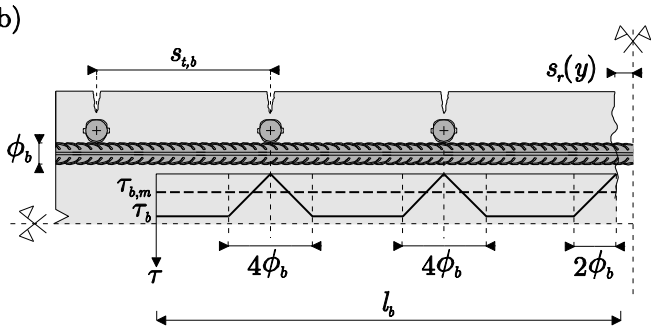

c)

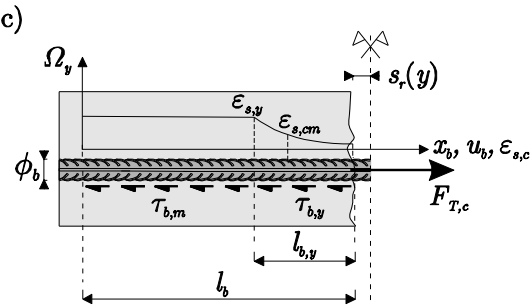

Figure 10. a) Modified local perfect-plastic bond-slip model; b) Influence of transverse cracking on bond strength along the reinforcing bar length; c) Modified pull-out model and influence of yielding on bond strength

Based on the modified pull-out model of Figure $10 \mathrm{c}$ ), the equilibrium of the bar [28] leads to:

$$
\frac{d^{2} u_{b}}{d x_{b}^{2}}-\frac{4 \tau}{E_{s e} \phi_{b}}=0
$$

Along the deformation process, the rebar initially behaves elastically with a constant bond strength $\tau_{b, m}$, until it yields and behaves elasto-plastically with the yielded length under a constant bond strength $\tau_{b, y}$, as depicted in Figure $10 \mathrm{c}$ ). Integrating Equation (30) for an elastic rebar and considering the origin of $x_{b}$ and $u_{b}$ as the point within the rebar with no strains and displacements, leads to the following expressions for the rebar slip $u_{b}$ and the rebar longitudinal strain $\varepsilon_{s, c}$ :

$$
u_{b}\left(x_{b}\right)=\frac{2 \tau_{b, m}}{E_{s e} \phi_{b}} x_{b}^{2} \quad \varepsilon_{s, c}\left(x_{b}\right)=\frac{\partial u_{b}}{\partial x_{b}}=\frac{4 \tau_{b, m}}{E_{s e} \phi_{b}} x_{b}
$$

Combining the previous expressions for $x_{b}=l_{b}$ (begin of the axial crack) and equating the rebar slip $u_{b}$ $\left(l_{b}\right)$ at the crack to $s_{\mathrm{r}}(y)$ leads to the following strain-displacement relationship along the axial crack:

$$
\varepsilon_{s, c}(y)=4 \cdot \sqrt{\frac{s_{r}(y) \tau_{b, m}}{2 E_{s e} \phi_{b}}}
$$

This equation holds until the reinforcement yields, which occurs for relative displacements larger than:

$$
\mathrm{s}_{y, r}=\frac{f_{s y} \varepsilon_{s, y} \phi_{b}}{8 \tau_{b, m}}
$$

For larger relative displacements, the rebar behaves elastic-plastically and is modelled as an elastic bar using an effective Young's modulus, $E_{s, e f f}$, and a reduced bond strength, $\tau_{b, y}$. This effective modulus varies from $E_{s e}$ in the elastic to $E_{s p}$ in the plastic or rather hardening range. In order to avoid computational problems due to an abrupt transition immediately after yielding from $E_{s e}$ to $E_{s p}$, a simple polynomial or exponential transition curve for describing $E_{s, e f f}$, depending on the rebar's slip, can be used. Hence, Equation (32) is also valid for the elasto-plastic stage of the reinforcing bar, leading to the following non-linear relationship:

$$
\varepsilon_{s, c}(y)=\varepsilon_{s, y}+4 \cdot \sqrt{\frac{\left(s_{r}(y)-\mathrm{s}_{y, r}\right) \tau_{b, \mathrm{y}}}{2 E_{s, e f f} \phi_{b}}}
$$


The effect of yielding is implemented by means of the parameter $\Omega_{y}$, which is described by an exponential function and depends on $\varepsilon_{s, c}(y)$. In order to simplify its calculation, a constant value of onethird of the maximum yield steel strain is assumed along the yielded bonding length:

$$
\varepsilon_{s, c m}(y)=\varepsilon_{s, y}+\frac{\varepsilon_{s, c}(y)-\varepsilon_{s, y}}{3}
$$

Equation (34) holds until the ultimate axial strain of the reinforcing steel is reached, which occurs for the relative displacement:

$$
\varepsilon_{s, c m}(y)=\varepsilon_{s, y}+\frac{\varepsilon_{s, c}(y)-\varepsilon_{s, y}}{3}
$$

where $\tau_{b, u}$ is the average value of the bond strength when $\varepsilon_{\mathrm{s}, \mathrm{c}}(y)=\varepsilon_{\mathrm{s}, \mathrm{u}}$. The relative displacement $s_{u, r}$ does not depend on $E_{s, e f f}$, and, therefore, the chosen transition curve is not relevant for the final result.

In summary, the strain-displacement relationship along the tensile zone range, $0 \leq y \leq y_{c r}$, of the axial crack can be expressed as:

$$
\varepsilon_{s, c}(y)= \begin{cases}4 \cdot \sqrt{\frac{s_{r}(y) \tau_{b, m}}{2 E_{s e} \phi_{b}}} & \text { for } 0 \leq s_{r}(y) \leq \mathrm{s}_{y, r} \\ \varepsilon_{s, y}+4 \cdot \sqrt{\frac{\left(s_{r}(y)-\mathrm{s}_{y, r}\right) \tau_{b, y}}{2 E_{s, e f f} \phi_{b}}} & \text { for } \mathrm{s}_{y, r}<s_{r}(y)<\mathrm{s}_{u, r}\end{cases}
$$

By means of the previously defined strains and the implemented material models, it is possible to calculate the tensile forces acting along the axial crack.

\subsubsection{Equilibrium relationships}

As a final step, the in-plane equilibrium relationships of the slab are considered, as schematically depicted in Figure 11. Herein, it is implicitly assumed that no in-plane shear forces act along the symmetry axes of an in-plane structure. It must also be noted that the distribution of membrane forces are not necessarily linear as depicted in Figure 11.

a)

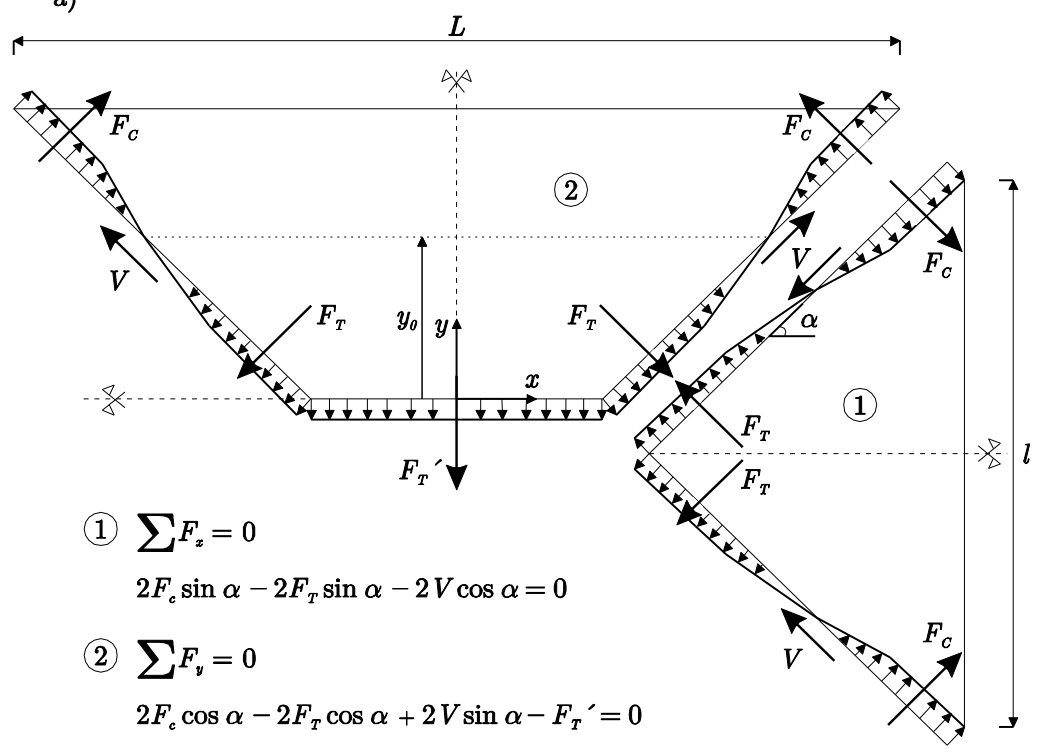

b)

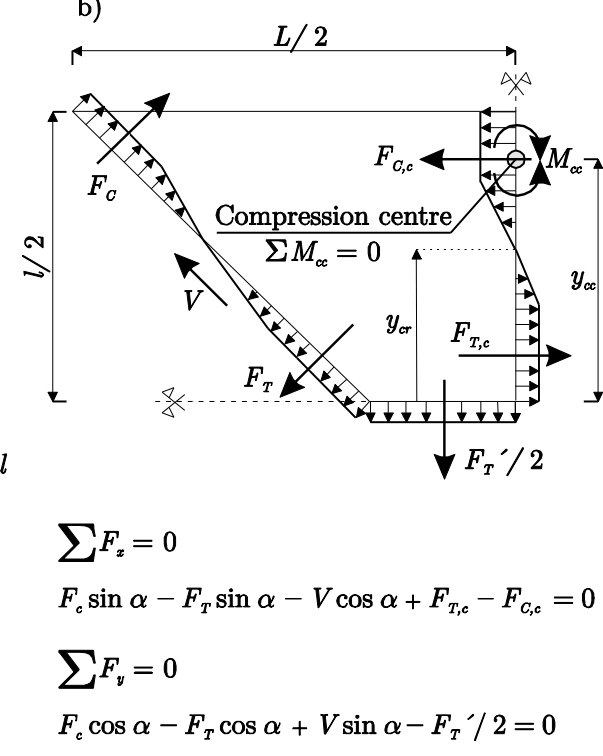

Figure 11. a) In-plane equilibrium of the slab's segments; b) In-plane equilibrium of a trapezoidal segment of the slab considering the internal forces along the axial crack

For equilibrium in the $x$-direction of the triangular slab segment (1), the following relationship is obtained: 


$$
V=\left(F_{c}-F_{T}\right) \tan \alpha
$$

Considering equilibrium in the $y$-direction of the trapezoidal segment (2), yields:

$$
\left(F_{c}-F_{T}\right) \cos \alpha-\frac{F_{T}^{\prime}}{2}=-V \sin \alpha
$$

By combining Equation (38) and (39), a new relationship is obtained linking the membrane forces along the yield lines, which defines the first equilibrium condition for the two unknowns:

$$
F_{c}-F_{T}=\frac{F_{T}^{\prime}}{2} \cos \alpha
$$

Considering the internal forces along the axial crack, as depicted in Figure $11 \mathrm{~b}$ ), and balancing forces in the $x$-direction, the following expression is obtained:

$$
\left(F_{c}-F_{T}\right) \sin \alpha+F_{T, c}=F_{C, c}+V \cos \alpha
$$

Considering Equation (38), Equation (41) results in:

$$
F_{T, c}=F_{C, c}
$$

Hence, the internal forces along the axial crack are balanced. By means of the known tensile forces acting along the axial crack, it is possible to calculate the forces and corresponding strain distribution at the compression zone. Assuming a linear distribution, the axial strains $\varepsilon_{s, c}(y)$ along the compression zone range $y_{c r} \leq y \leq l / 2$ can be expressed as:

$$
\varepsilon_{s, c}(y)=\frac{\varepsilon_{s, c}(l / 2)}{\frac{l}{2}-y_{c r}}\left(y-y_{c r}\right)
$$

where $\varepsilon_{s, c}(l / 2)$, represents the maximum compressive strains of the axial crack and can be calculated integrating Equation (42) and considering the described material models and strain distributions:

$$
\int_{0}^{y_{c r}}\left|\varepsilon_{s, c}(y) E_{s}\left(\varepsilon_{s, c}(y)\right) A\right| d y=\int_{y_{c r}}^{1 / 2}\left|\varepsilon_{s, c}(y) E_{c m}\left(\varepsilon_{s, c}(y)\right) A\right| d y
$$

Solving this nonlinear equation, the strains and corresponding membrane forces along the axial crack are completely described and the compression centre can be determined:

$$
y_{c c}=y_{c r}+\frac{\int_{y_{c r}}^{1 / 2}\left|\varepsilon_{s, c}(y) E_{c m}\left(\varepsilon_{s, c}(y)\right) A\left(y-y_{0}\right)\right| d y}{\left|F_{c, c}\right|}
$$

Once the axial forces along the yield lines and the axial crack are known, it is possible to set an additional equilibrium condition based on the formation of an in-plane plastic hinge at the compressed zone (see Section 2). This phenomenon is implemented in the proposed approach by imposing the equilibrium of in-plane bending moments at the compression centre of the axial crack:

$$
\sum M_{c c}=0
$$

As illustrated in the previous derivations, only two unknowns, $\mu(0)$ and $y_{0}$, completely describe the distributions of membrane forces along the yield lines and the axial crack. These force distributions must satisfy both nonlinear Equations (40) and (46), which can be solved by numerical integration and discretization of the domain. In general, these equations do not comply with the assumed distributions and an iterative procedure is required to find the values of $\mu(0)$ and $y_{0}$ that satisfy them.

\subsubsection{Estimation of the load-bearing capacity of the slab}

Once a distribution of concrete depths is found for a specific deflection, which satisfies both kinematics and equilibrium, it is possible to estimate the load-bearing capacity of the slab. This is done by 
considering moment equilibrium of each individual slab segment about the axes of rotation. Assuming stepped yield lines in the reinforcement directions, the torsional moments and in-plane shear forces do not have to be considered, since they are zero in those directions [24]. Hence, only the vertical shear forces acting along the yield lines have to be determined.

a)

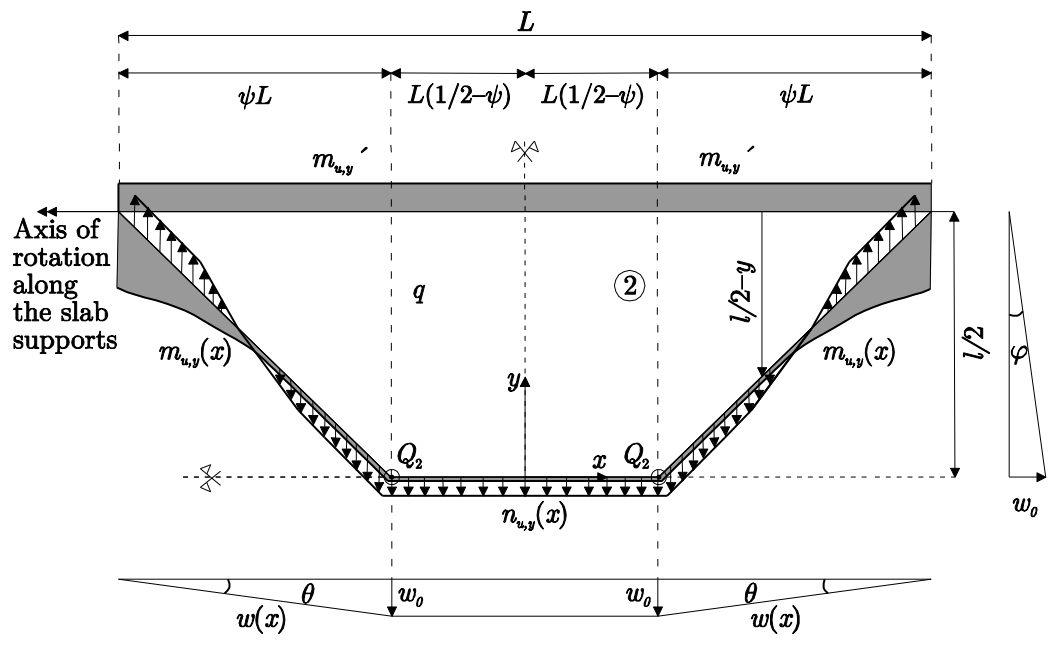

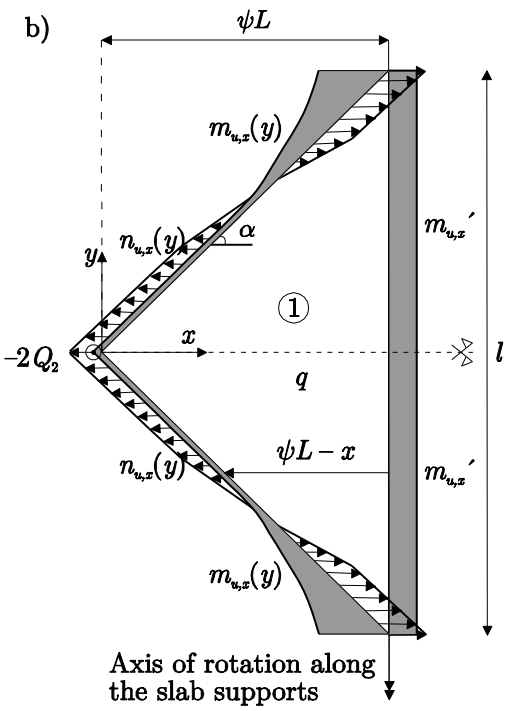

Figure 12. a) Free-body diagram of the trapezoidal slab segment (2); b) Free body diagram of the triangular slab segment (1)

In order to calculate these vertical shear forces, an approach described in [23] is used, which involves the calculation of statically equivalent nodal forces. This is performed by replacing the actual shear forces acting at each straight length of yield line by two statically equivalent nodal forces, one at each end of the length of yield line. Applying this approach results in the following relationship between the equivalent nodal shear forces at the intersection of the three positive yield lines:

$$
Q_{1}=-2 Q_{2}
$$

The direction and magnitude of these nodal shear forces results from considering equilibrium of the isolated slab segments (1) and (2), as depicted in Figure 12. Considering moment equilibrium along the slab supports and taking into account the kinematic and geometric relationships defined in 4.3 .3 and Equation (47), the equilibrium of the triangular element (1) leads to the following expression:

$$
q=\frac{12}{l \psi^{2} L^{2}}\left[\int_{0}^{\frac{l}{2}}\left(m_{u, x}(y)+m_{u, x}{ }^{\prime}(y)\right) d y+\int_{0}^{\frac{l}{2}} n_{u, x}(y)\left(\frac{l}{2}-y\right) \frac{2 w_{0}}{l} d y \pm Q_{2} \psi L\right]
$$

Considering equilibrium of the trapezoidal slab segment (2), the following relationship is obtained:

$$
\begin{aligned}
q= & \frac{48}{\gamma l^{3}(3-4 \psi)}\left[\int_{0}^{\frac{L}{2}}\left(m_{u, y}(x)+m_{u, y}(x)\right) d x+\int_{0}^{L}\left(\frac{1}{2}-\psi\right) n_{u, y}(x) w_{0} d x\right. \\
& \left.+\int_{L\left(\frac{1}{2}-\psi\right)}^{\frac{L}{2}} n_{u, y}(x)(\psi L-x) \frac{w_{0}}{\psi L} d x \mp Q_{2} \frac{l}{2}\right]
\end{aligned}
$$

For simply supported slabs, the negative slab moments $m_{u, x^{\prime}}$ and $m_{u, y^{\prime}}$ are zero.

Hence, two expressions for the load-bearing capacity $q$ of the slab depending on $Q_{2}$, are obtained. Since this bearing capacity must be equal for the two individual segments and, therefore, for the entire slab, Equation (48) and (49) must be also equal, and the value of $Q_{2}$ can be obtained. Once the nodal shear forces are known, the actual load-bearing capacity $q$ for a specific deflected state of the slab can be obtained by application of either Equation (48) and (49). 


\subsubsection{Failure criteria}

The procedure is applied for increasing deflections until nominal failure is predicted. Once failure occurs, the slab is assumed to lose all load-bearing capacity and therefore the calculation of the loaddeflection relationship of the slab is interrupted. The values for the central vertical deflection at failure and the corresponding load-bearing capacity are defined as $w_{\text {lim }}$ and $q_{\text {lim }}$, respectively. The proposed design approach considers two possible failures:

a) Compressive failure due to concrete crushing

Failure along the compression ring is implemented differently at the slab corners and support mid-points, next to the axial crack.

The slab corners are subjected to the combined action of bending and compression forces and failure is predicted by limiting the maximum compressive strains $\varepsilon_{\text {corner }}$ at the corners to the ultimate compressive concrete strain. Estimation of these strains is complex and a simplified approach is used. Strains are assumed to only develop at the corners once the collapse mechanism is completely formed, which results in the following vertical deflection:

$$
w_{y, \text { cormer }}=\max \left(w_{u}, \frac{q_{u} w_{y}}{q_{y}}\right)
$$

At larger deflections, although the cross-section at the corners has yielded, $\varepsilon_{\text {conner }}$ is estimated assuming elastic behaviour of the materials under the combined action of bending moments and axial forces:

$$
\varepsilon_{\text {corner }}=\frac{n_{\text {corner }}}{A E_{c m}}+c_{\text {corner }} \frac{m_{\text {comer }}}{E_{c m} I_{e f f}}
$$

In order to consider the effects of yielding, an effective moment of inertia $I_{\text {eff }}$ of the cross section is used. The calculation of $I_{\text {eff }}$ is based on the procedure proposed by Gunay and Sucuoglu [29]. For the initial yielding, which occurs at only one end of the cross-section, $I_{\text {eff }}$ can be estimated with:

$$
I_{e f f}=\frac{I_{c r}}{2}\left(1+\frac{w_{y, \text { corner }}}{w_{0}}\right)
$$

For increasing deflections, the other end of the member will eventually yield. The deflection for which yielding first occurs at the other end of the cross-section is defined as $w_{y, \text { corner, },}$, which can be estimated with the implemented material models. For deflections larger than $w_{y, c o r n e r, 2}, I_{\text {eff }}$ can be estimated with:

$$
I_{\text {eff }}=\frac{I_{c r}}{2}\left(\frac{w_{y, \text { corner }, 2}}{w_{0}}+\frac{w_{y, \text { corner }}}{w_{0}}\right)
$$

Once $\varepsilon_{\text {corner }}$ reaches the ultimate compressive concrete strain $\varepsilon_{c, u}$ failure of the slab is assumed to occur.

On the other hand, the slab at the mid-points of the supports is subjected to pure axial compressive forces. Here, failure is similarly predicted by limiting the maximum compressive strains, $\varepsilon_{s, c}(l / 2)$, (Equations (43) and (44)), to the ultimate compressive concrete strain value. Such failures occur, generally, in heavily reinforced slabs.

b) Reinforcement rupture at the axial crack

In theory, the axial crack is subjected only to axial tensile forces. Hence, failure is again predicted by limiting the maximum tensile rebar strains $\varepsilon_{s, c}(0)$ at the slab mid-point (Equation (37)) to the ultimate tensile strain of steel $\varepsilon_{s, u}$.

\section{Comparative assessment}

\subsection{Introduction}

In order to assess the accuracy and reliability of the proposed new and some of the existing design approaches, the results of the numerical simulations are compared with experimental results. 
Results from 43 laterally unrestrained slab tests from different experimental campaigns are used for this comparative assessment, namely, a full-scale slab test conducted at BRE [14], 26 small-scale tests performed by Bailey and Toh [16] and 16 small-scale tests conducted by Cashell et al. [17].

Numerical simulations of the 43 specimens with the new design approach were performed, as well as with the other two existing analytical approaches that include failure criteria, namely, the approach by Bailey and Toh [20] and the approach by Omer et al. [21]. These simulations were performed using the experimental material and geometrical average values provided by the authors who conducted the considered campaigns $[14,16,17]$. Thereby, not only the individual comparison of experimental and simulation results are obtained for each approach, but also the performance between the different approaches can be evaluated.

\subsection{Comparison and discussion of the experimental and estimated load-deflection relationships}

The load-deflection relationship of the 43 specimens estimated with the different design approaches were calculated. The relationships for several of these specimens are plotted in Figure 13. The applied load $q$ and the vertical deflections $w_{0}$ were normalised to the ultimate flexural load $q_{u}$ given by the classical yield-line theory and the average effective depth $d$ of the reinforcement, respectively.

Figure 13 shows that the estimated load-deflection relationships of the proposed design approach agree quite well with the experimental ones to most of their extent for most of the considered specimens.

The predictions for the pre-yielding and transitional stage, however, show a larger deviation from the test results due to the low flexural stiffness of the small-scale specimens. The approach is conceived for typical slabs, which develop a flexural collapse mechanism at relatively low deflections and membrane action for deflections larger than the ultimate deflection $w_{u}$ when the supports reverse from expanding to contracting. However, most of these small-scale specimens yield at larger deflections than $w_{u}$. Hence, the approach artificially assigns a stiffer behaviour to the slab than in reality, as it assumes that the flexural collapse mechanism has developed completely (and consequently $q_{u}$ is reached) before membrane action starts, leading to poor estimations of the load-deflection relationship at these initial stages.

This agreement was expected to be much better for full-scale specimens. Unfortunately, the fullscale specimen by Bailey et al. had such a low reinforcement ratio that it reached $q_{u}$ with its self- weight. Hence, there is no record of intermediate points of the load-deflection relationship along the pre-yielding and transitional stage as can be seen in Figure 13.

In addition, most of the specimens had either cold-worked or stainless steel reinforcement, which do not exhibit a distinct yield plateau. Since perfect-plastic behaviour of materials is assumed, disagreements between the load-deflection relationships observed in experimental tests and those obtained in simulations are to be expected.

The approach by Bailey and Toh exhibits for most specimens a similar slope for the membrane action stage as in the new approach. However, this approach generally leads to rather conservative failure predictions, especially for failure due to concrete crushing.

The membrane action slope of the approach by Omer et al. is steeper than those of other methods for most of the specimens. In general, the approach by Omer et al. overestimates the load and deflection at failure compared to the new approach.

Finally, the considered ultimate deflection $w_{u}$ at which membrane forces start to develop for the novel design approach agrees quite well with the apparent starting point of membrane action derived from the experimental curves, confirming the suitability of the proposed kinematic model.

\subsection{Comparison and discussion of the experimental and predicted loads and deflections at failure}

The key results provided by these design approaches are loads and vertical deflections at failure. In order to assess the accuracy of these methods, the experimental results and simulation predictions for the 43 specimens at failure are compared. This comparative assessment includes a qualitative graphical representation and a quantitative statistical analysis.

For the graphical representation, the simulated predictions for each approach are plotted versus the experimental results. Here again, the load and deflection at failure are normalised to $q_{u}$ and $d$, 

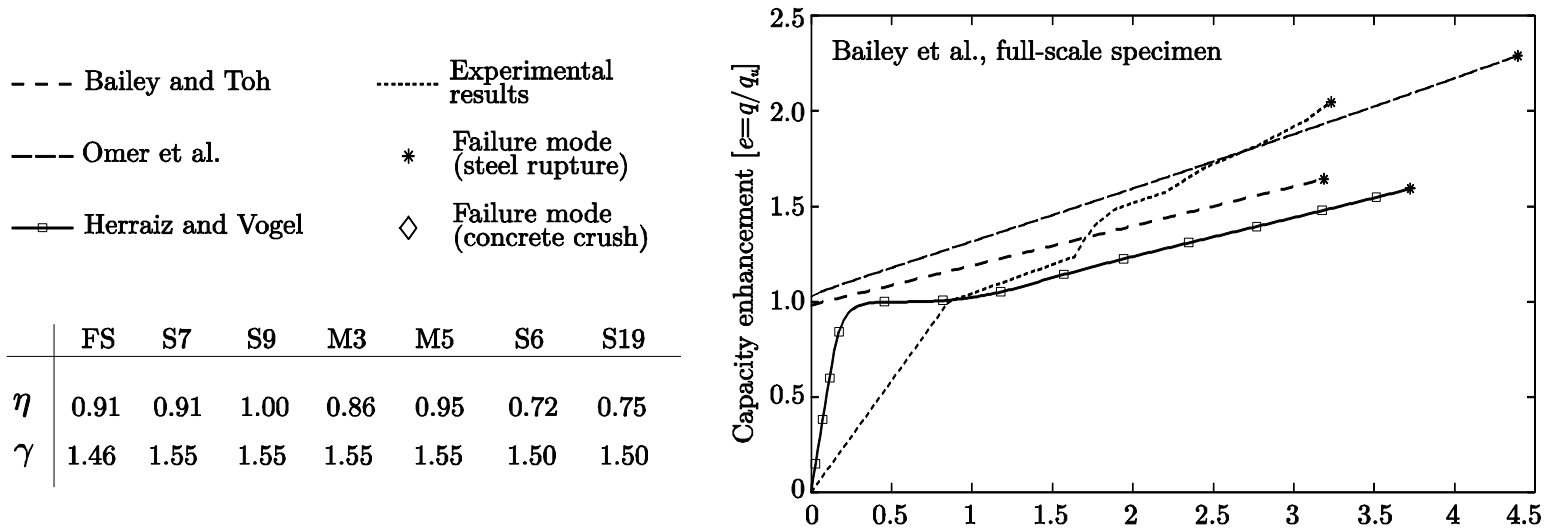

\begin{tabular}{c|ccccccc} 
& FS & S7 & S9 & M3 & M5 & S6 & S19 \\
\hline$\eta$ & 0.91 & 0.91 & 1.00 & 0.86 & 0.95 & 0.72 & 0.75 \\
$\gamma$ & 1.46 & 1.55 & 1.55 & 1.55 & 1.55 & 1.50 & 1.50
\end{tabular}
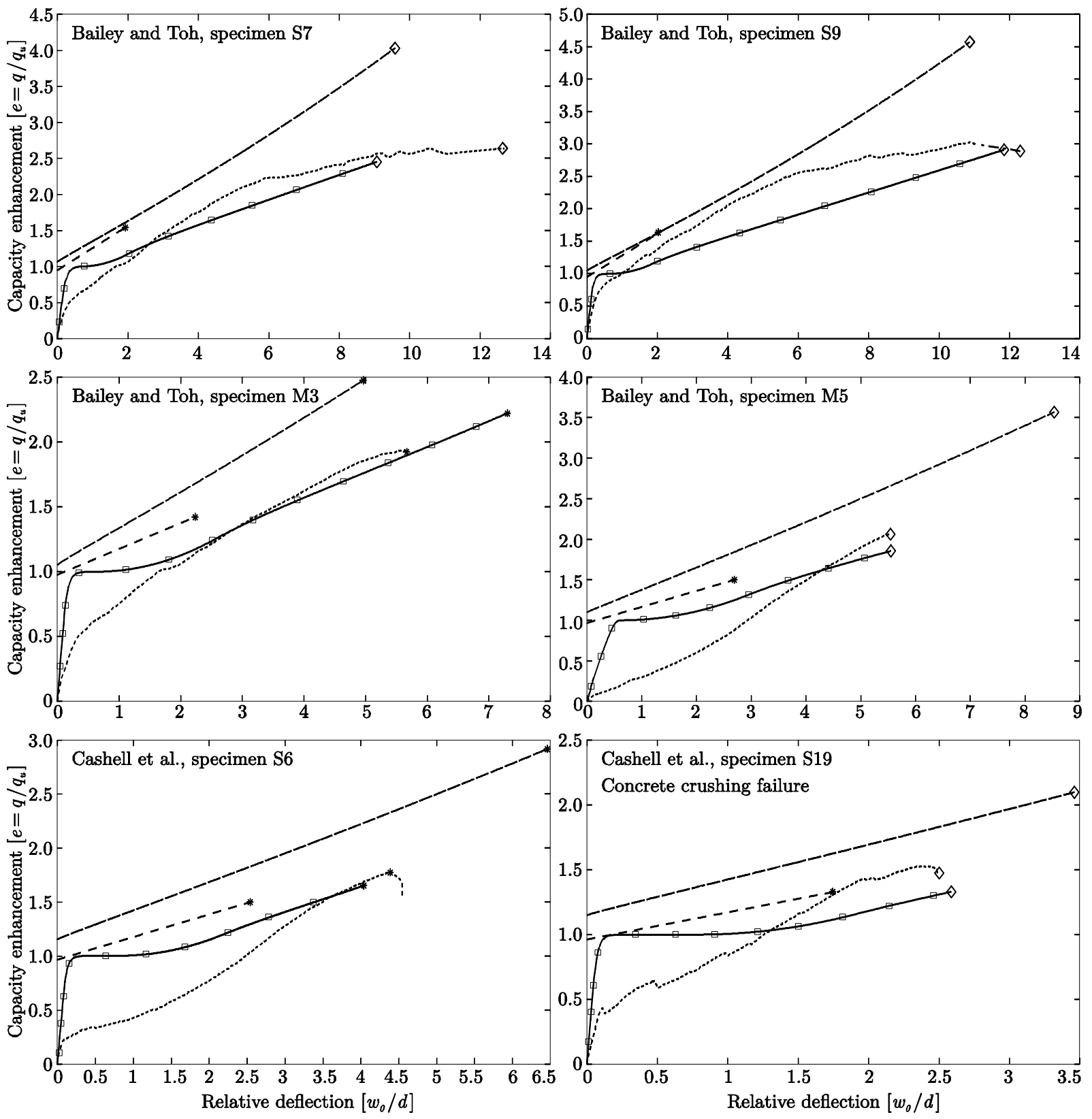

Figure 13. Comparison of the experimental and estimated load-deflection relationships for different design approaches

respectively. Additionally, a line representing an ideal perfect correlation between experimental and simulated results is plotted. The vertical deviations between the observation points and this ideal line represent the error for each prediction. Furthermore, the regression line for these observations, based on 
Ordinary Least Squares (OLS), is also displayed. The closer this OLS regression line to the ideal line is, the more accurate and realistic predictions the approach provides. Finally, the 95\% confidence and prediction intervals are depicted. They provide a simple way to evaluate the scatter of the predictions, offering a good graphical estimation of the precision obtained for each approach. The narrower these intervals are, the more precise the method is.

Two broadly-recognised parameters are used to statistically validate the different approaches. Firstly, the $R^{2}$ coefficient of determination is estimated to evaluate the goodness of fit of the predictions to the ideal line for a perfect correlation. Negative values of $R^{2}$ are possible, since the predictions that are compared to the corresponding outcomes were not derived from a model-fitting procedure using those values [30]. Negative values imply a poor agreement between test results and predictions. Values close to unity imply a good agreement between them.

Secondly, the Mean Absolute Percentage Error (MAPE) [31] is used to evaluate the average error between the experimental and simulation results. Using the same set of actual experimental values, the MAPE is symmetrical. This property is convenient for method evaluation, since the MAPE is not biased and provides a reliable value of the error.

The results from these graphical and statistical assessments for loads and deflections at failure are summarized in Figure 14 for the different approaches. Figure 14, shows that the comparative results for loads and deflections at failure are quite similar within the same design approach. While the OLS regression line of the new approach and the one by Omer et al. are similar to the line of perfect correlation, meaning that the predictions are unbiased, the regression lines of the approach by Bailey and Toh are almost horizontal, which means that this approach tends to underestimate the failure quantities.

Furthermore, the proposed approach displays narrow prediction and confidence intervals which correspond to the ideal line, showing that this approach is both accurate and precise. The approach by Omer et al. has slightly wider intervals and only partially corresponds to the ideal line, meaning that the approach is less accurate and precise. Finally, the approach by Bailey and Toh also displays narrow intervals, which barely correspond to the ideal line, underlining the tendency of this approach for resulting in overly conservative failure predictions.

The values of the $R^{2}$ and the MAPE coefficients displayed in Figure 14 for loads and deflections at failure are similar within each of the design approach. The evaluation of $R^{2}$ shows a clearly improved performance by the new approach compared to the other ones. The proposed approach is robust in terms of the prediction of loads and deflections at failure for the considered set of slabs. The approach by Omer et al. yields lower positive values for $R^{2}$ than the proposed approach, and the predictions from the approach by Bailey and Toh deviate significantly from the test results, especially for the most ductile specimens, yielding large negative values for $R^{2}$.

The evaluation of the MAPE confirms the $R^{2}$ values, but the differences between the approaches are not as significant for this coefficient. Again, the proposed approach exhibits the lowest mean absolute error, while the other approaches by Omer et al. and Bailey and Toh provides higher values for the MAPE for both predicted failure quantities. These MAPE values appear to be high even for the new design approach. The obtained MAPE values for the proposed approach are quite satisfactory, however, taking into account the large number of involved uncertain parameters and complex interactions occurring until the failure of the slab. Current advanced finite-element based methods do not offer a better accuracy on the failure predictions [19] and require more computation time.

\section{Conclusions}

The proposed design approach, based on equilibrium and kinematics, is compared with 43 experimental tests on laterally unrestrained slabs conducted by different authors. For most of the considered set of specimens, the load-deflection relationships estimated with this approach are in good agreement with the experimental ones. Moreover, the described graphical representation and the statistical parameters show a clear advantage when using the proposed approach compared to the other ones for the estimation of the load and deflection at failure. The accuracy of these failure predictions underlines the suitability 
Small-scale tests by Cashell et al.

$\square$ Small-scale tests (M-series) by Bailey and Toh

$\diamond$ Small-scale tests (S-series) by Bailey and Toh

* Full-scale test by Bailey et al.

Comparison of capacity enhancements $\left[e=q_{\mathrm{lim}} / q_{u}\right]$
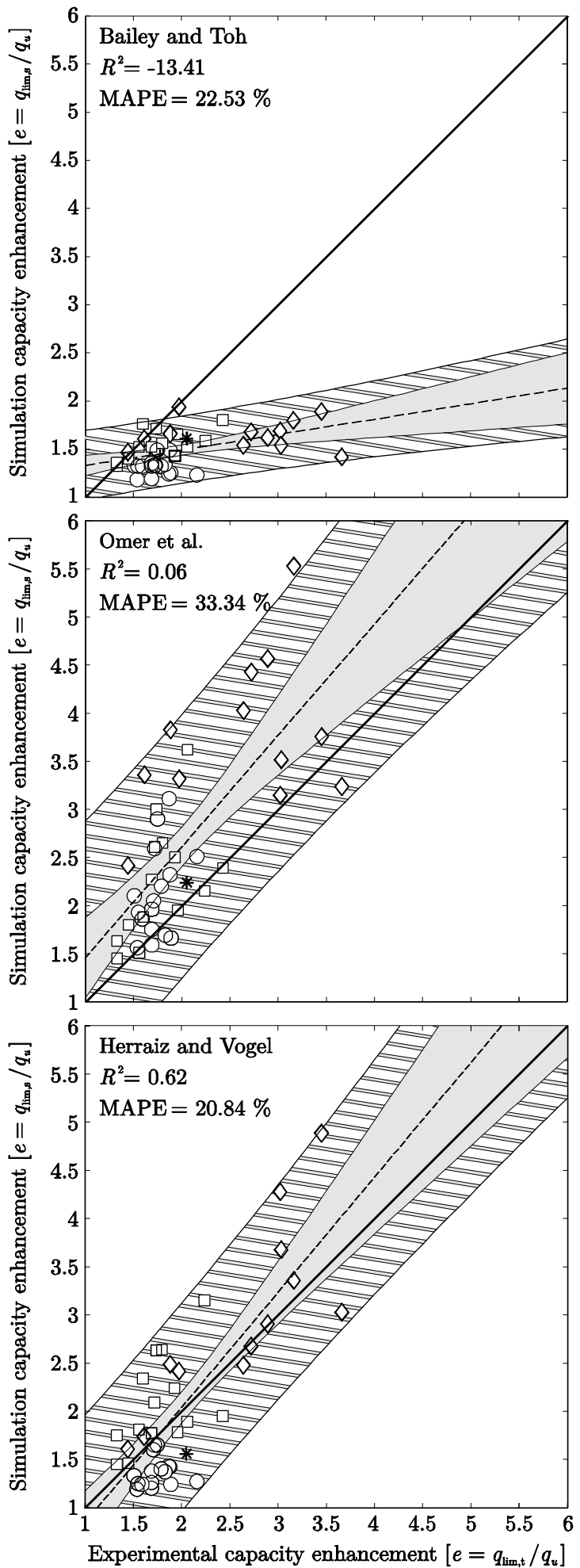

- Ideal line for a perfect test-simulation correlation - - Line of best-fit based on ordinary least squares $95 \%$ confidence interval for the average value $95 \%$ prediction interval for individual observations

Comparison of relative vertical deflections $\left[w_{\lim } / d\right]$
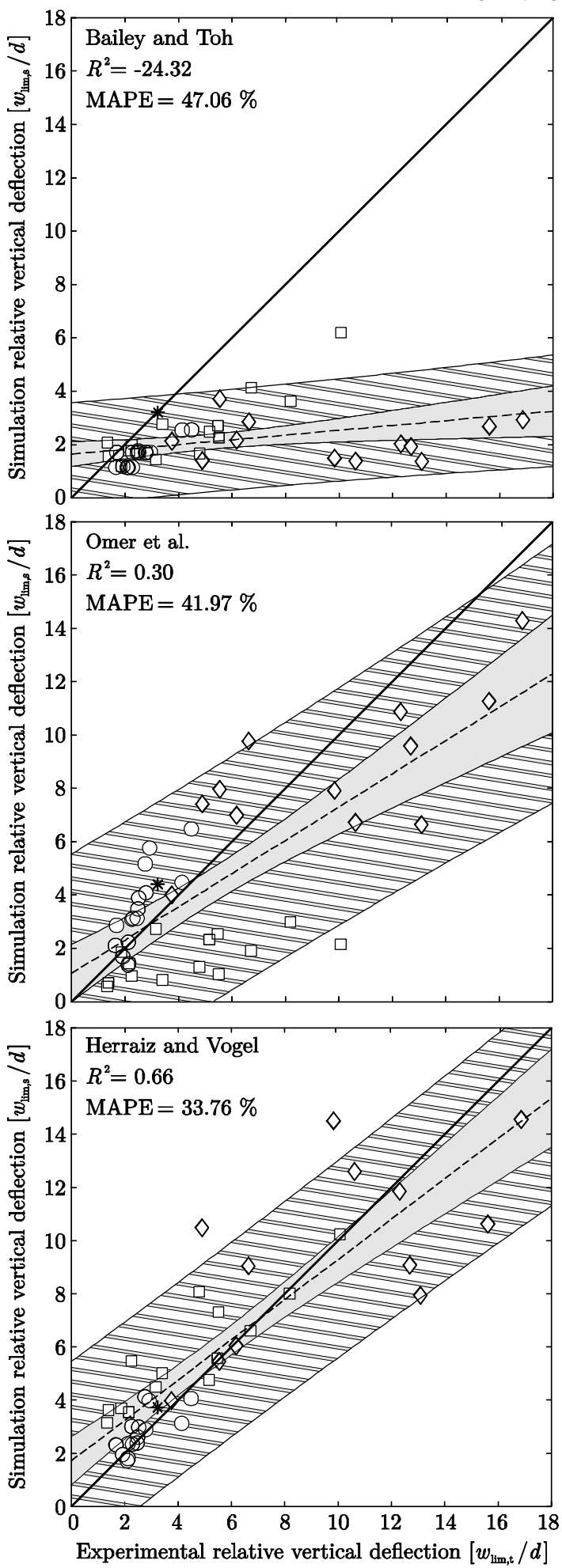

Figure 14. Statistical and graphical comparison of the tests results and design approach predictions for the normalised loads and vertical deflection at failure

of the proposed failure criteria for the novel approach.

The statistical parameters and graphical representation of the failure predictions obtained with the two other analysed approaches lead to different evaluations. The predictions from the approach by Omer 
et al. correlate reasonably well with the experimental results, especially for deflections at failure. The load-bearing capacities are slightly overestimated in general, but the assumed failure criteria seem to be robust. On the other hand, the predictions obtained using the approach by Bailey and Toh underestimate the experimental results for both, loads and deflections at failure. The conservative failure criteria [20] lead to significant underestimations of the predicted deflections at failure, which directly influence the predicted load-bearing capacities.

Based on the results of this comparative assessment, the approach by Omer et al. seems to be useful as a simple alternative to analyse the behaviour of laterally unrestrained slabs. The fact that the bond strength is required as a direct input parameter, however, makes this approach less appealing for practical application. Moreover, this approach does not consider the $M-N$ interaction along the yield lines. This limitation may not have a large impact on the predictions for the considered set of smallscale specimens, since the flexural component is relatively small. In full-scale specimens, however, this interaction plays an important role, potentially compromising the accuracy of this approach.

The deviations and errors between test results and predictions obtained using the approach by Bailey and Toh are significant and therefore the authors discourage the use of this approach for failure predictions of laterally unrestrained slabs. Finally, the comparison with the set of considered specimens show that the novel design approach generally leads to moderate errors and deviations in the predictions and could therefore be used as an alternative to more complex and time-consuming approaches, without resulting in a significant loss of accuracy.

\section{Nomenclature}

\begin{tabular}{|c|c|c|c|}
\hline$A$ & cross-sectional area per unit width & $e_{\theta^{\prime}}$ & partial elongation orthogonal to the \\
\hline$C$ & $\begin{array}{l}\text { resultant of the compression forces in } \\
\text { a cross-section per unit width }\end{array}$ & & $\begin{array}{l}\text { diagonal yield lines for the triangular } \\
\text { slab regions }\end{array}$ \\
\hline$c$ & $\begin{array}{l}\text { depth of the compression zone } \\
\text { (surface to neutral axis) }\end{array}$ & $e_{\varphi}^{\prime}$ & $\begin{array}{l}\text { partial elongation orthogonal to the } \\
\text { diagonal yield lines for the }\end{array}$ \\
\hline \multirow[t]{2}{*}{$c(y)$} & concrete depth distribution along the & & trapezoidal slab regions \\
\hline & diagonal yield lines & $F_{C}$ & resultant of the compression forces \\
\hline$c(x)$ & $\begin{array}{l}\text { concrete depth distribution along the } \\
\text { yield line parallel to the longer span }\end{array}$ & $F_{C, c}$ & $\begin{array}{l}\text { along the diagonal yield lines } \\
\text { resultant of the compression forces }\end{array}$ \\
\hline$c_{A B}$ & $\begin{array}{l}\text { concrete depth for simultaneous } \\
\text { failure of concrete and reinforcement }\end{array}$ & $F_{T}$ & $\begin{array}{l}\text { along the axial crack } \\
\text { resultant of the tensile forces along }\end{array}$ \\
\hline$c_{\text {corner }}$ & $\begin{array}{l}\text { concrete depth at the corners of the } \\
\text { slab }\end{array}$ & $F_{T}^{\prime}$ & $\begin{array}{l}\text { the diagonal yield lines } \\
\text { resultant of the tensile forces along }\end{array}$ \\
\hline$c_{n}$ & $\begin{array}{l}\text { averaged concrete depth of the } \\
\text { neutral axis for the ultimate pure }\end{array}$ & & $\begin{array}{l}\text { the yield line parallel to the longer } \\
\text { span }\end{array}$ \\
\hline \multirow[b]{2}{*}{$c_{n}^{\prime}$} & positive bending moment $(n=0)$ & $F_{T, c}$ & resultant of the tensile forces along \\
\hline & $\begin{array}{l}\text { averaged concrete depth of the } \\
\text { neutral axis for the ultimate pure } \\
\text { negative bending moment }(n=0)\end{array}$ & $f_{c m}$ & $\begin{array}{l}\text { the axial crack } \\
\text { average compressive cylinder } \\
\text { strength of concrete }\end{array}$ \\
\hline$d$ & effective depth of the reinforcement & $f_{s, y}$ & yield strength of reinforcing steel \\
\hline$d_{c c}$ & height of the axis of rotation & $f_{s, u}$ & ultimate tensile strength of \\
\hline$d_{r}$ & lever arm of the neutral axis & & reinforcing steel \\
\hline$E_{c m}$ & Young's modulus for concrete & $h$ & slab thickness \\
\hline$E_{s}$ & $\begin{array}{l}\text { Young's modulus for reinforcing } \\
\text { steel }\end{array}$ & $I_{\text {eff }}$ & $\begin{array}{l}\text { effective moment of inertia of the } \\
\text { cross section at the corners }\end{array}$ \\
\hline$E_{s, \text { eff }}$ & $\begin{array}{l}\text { effective Young's modulus for } \\
\text { reinforcing steel }\end{array}$ & $I_{c r}$ & $\begin{array}{l}\text { moment of inertia of the cracked } \\
\text { cross section }\end{array}$ \\
\hline$E_{s e}$ & $\begin{array}{l}\text { elastic Young's modulus for } \\
\text { reinforcing steel }\end{array}$ & $\begin{array}{l}L \\
l\end{array}$ & $\begin{array}{l}\text { longer span of the rectangular slab } \\
\text { shorter span of the rectangular slab }\end{array}$ \\
\hline$E_{s p}$ & post-yielding hardening modulus for & $l_{b}$ & rebar bonding length \\
\hline & reinforcing steel & $l_{b, y}$ & rebar yielded bonding length \\
\hline$e_{x}(y)$ & $\begin{array}{l}\text { partial elongations of the yield lines } \\
\text { in the } x \text {-direction at the neutral axis }\end{array}$ & $M_{c c}$ & $\begin{array}{l}\text { resultant of the in-plane moments at } \\
\text { the compression centre }\end{array}$ \\
\hline
\end{tabular}




\begin{tabular}{|c|c|c|c|}
\hline $\begin{array}{l}m \\
m_{\text {corner }}\end{array}$ & $\begin{array}{l}\text { bending moment per unit width } \\
\text { bending moment per unit width at the } \\
\text { corners of the slab }\end{array}$ & $w_{\text {ini }}$ & $\begin{array}{l}\text { central vertical deflection at which a } \\
\text { specific point of the axial crack starts } \\
\text { opening }\end{array}$ \\
\hline$m_{u, 0}$ & $\begin{array}{l}\text { ultimate pure positive bending } \\
\text { moment of a cross section per unit } \\
\text { width }(n=0)\end{array}$ & $w_{\lim }$ & $\begin{array}{l}\text { central vertical deflection } \\
\text { corresponding to failure }\end{array}$ \\
\hline \multirow[t]{2}{*}{$m_{u, 0^{\prime}}$} & $\begin{array}{l}\text { width }(n=0) \\
\text { ultimate pure negative bending } \\
\text { moment of a cross section per unit }\end{array}$ & $w_{u}$ & $\begin{array}{l}\text { central ultimate vertical deflection for } \\
\text { which membrane action is assumed } \\
\text { to begin in the new approach }\end{array}$ \\
\hline & width $(n=0)$ & $w_{y}$ & central vertical deflection \\
\hline \multirow[t]{2}{*}{$m_{u}$} & positive bending moment of a cross & & corresponding to first yielding \\
\hline & $\begin{array}{l}\text { section per unit width, caused by an } \\
\text { ultimate curvature }\end{array}$ & $w_{y, \text { corner }}$ & $\begin{array}{l}\text { central vertical deflection for which } \\
\text { strains begin to develop at the corners }\end{array}$ \\
\hline \multirow[t]{2}{*}{$m_{u}^{\prime}$} & $\begin{array}{l}\text { negative bending moment of a cross } \\
\text { section per unit width, caused by an }\end{array}$ & $w_{y, \text { corner }, 2}$ & $\begin{array}{l}\text { central vertical deflection for which } \\
\text { the cross-section completely yields }\end{array}$ \\
\hline & ultimate curvature & $x$ & coordinate defining positions in the \\
\hline$n$ & normal force per unit width & & longer span direction of the slab \\
\hline$n_{\text {corner }}$ & $\begin{array}{l}\text { normal force per unit width at the } \\
\text { corners of the slab }\end{array}$ & $x_{b}$ & $\begin{array}{l}\text { coordinate defining positions along } \\
\text { the bonding length of rebars }\end{array}$ \\
\hline$n_{u}$ & $\begin{array}{l}\text { normal force per unit width, caused } \\
\text { by an ultimate curvature }\end{array}$ & $y$ & $\begin{array}{l}\text { coordinate defining positions in the } \\
\text { shorter span direction of the slab }\end{array}$ \\
\hline$Q_{1,} Q_{2}$ & $\begin{array}{l}\text { statically equivalent nodal shear } \\
\text { forces }\end{array}$ & $y_{0}$ & $\begin{array}{l}\text { parameter defining the point of zero } \\
\text { axial forces along diagonal yield lines }\end{array}$ \\
\hline \multirow{4}{*}{$\begin{array}{l}q \\
q_{c r} \\
q_{l i m} \\
q_{u}\end{array}$} & applied uniform load & $y_{c c}$ & parameter defining the position of the \\
\hline & uniform load causing first cracking & & compression centre at the axial crack \\
\hline & uniform load causing failure & $y_{c r}$ & length of the tensile zone of the axial \\
\hline & $\begin{array}{l}\text { uniform ultimate flexural load given } \\
\text { by the classical yield-line theory }\end{array}$ & $\alpha$ & $\begin{array}{l}\text { crack } \\
\text { angle defining the yield line pattern }\end{array}$ \\
\hline $\begin{array}{l}q y \\
s(y)\end{array}$ & $\begin{array}{l}\text { uniform load causing first yielding } \\
\text { lateral displacements along the axial } \\
\text { crack }\end{array}$ & $\beta, \beta^{\prime}$ & $\begin{array}{l}\text { angles defining elongations of the } \\
\text { yield lines on the horizontal plane at } \\
\text { the axis of rotation }\end{array}$ \\
\hline$s_{\text {ini }}(y)$ & $\begin{array}{l}\text { lateral displacements along the axial } \\
\text { crack before membrane forces } \\
\text { develop }\end{array}$ & $\begin{array}{l}\gamma \\
\Lambda \\
\varepsilon\end{array}$ & $\begin{array}{l}\text { aspect ratio of the slab }(L / l) \\
\text { rotation ratio }(\varphi / \theta) \\
\text { generic cross-sectional axial strain }\end{array}$ \\
\hline \multirow[t]{2}{*}{$s_{r}(y)$} & $\begin{array}{l}\text { relative lateral displacements along } \\
\text { the axial crack }\end{array}$ & $\varepsilon_{s, c}$ & $\begin{array}{l}\text { longitudinal strain of the reinforcing } \\
\text { bars along the bonding length and }\end{array}$ \\
\hline & $\begin{array}{l}\text { relative displacement at the axial } \\
\text { crack causing yielding of rebars }\end{array}$ & $\varepsilon_{c}$ & $\begin{array}{l}\text { axial crack } \\
\text { concrete strain }\end{array}$ \\
\hline$s_{u, r}$ & $\begin{array}{l}\text { relative displacement at the axial } \\
\text { crack causing rupture of rebars }\end{array}$ & $\varepsilon_{c, 1}$ & $\begin{array}{l}\text { concrete strain at the maximum } \\
\text { compressive strength }\end{array}$ \\
\hline$s_{t, b}$ & $\begin{array}{l}\text { average spacing between reinforcing } \\
\text { bars in the } y \text {-direction }\end{array}$ & $\varepsilon_{\text {corner }}$ & $\begin{array}{l}\text { maximum compressive strains at the } \\
\text { corners of the slab }\end{array}$ \\
\hline$T$ & $\begin{array}{l}\text { resultant of the tensile forces in a } \\
\text { cross-section per unit width }\end{array}$ & $\begin{array}{l}\varepsilon_{c, u} \\
\varepsilon_{s}\end{array}$ & $\begin{array}{l}\text { ultimate compressive concrete strain } \\
\text { reinforcing steel strain }\end{array}$ \\
\hline \multirow[t]{2}{*}{$\begin{array}{l}u_{b} \\
u(y)\end{array}$} & $\begin{array}{l}\text { slip of the reinforcing bar } \\
\text { lateral displacements of the slab at the }\end{array}$ & $\varepsilon_{s, c m}$ & $\begin{array}{l}\text { assumed averaged yield steel strain } \\
\text { along the yield bonding length }\end{array}$ \\
\hline & axis of rotation in the $x$-direction & $\varepsilon_{s, y}$ & yield strain of reinforcing steel \\
\hline$u_{n}(y)$ & $\begin{array}{l}\text { lateral displacements of the slab at the } \\
\text { neutral axis for pure bending in the } x \text { - }\end{array}$ & $\varepsilon_{s, u}$ & $\begin{array}{l}\text { ultimate tensile strain of reinforcing } \\
\text { steel }\end{array}$ \\
\hline$V$ & $\begin{array}{l}\text { direction } \\
\text { resultant of the in-plane shear forces }\end{array}$ & $\eta$ & $\begin{array}{l}\text { coefficient of orthotropy } \\
\left(m_{u, 0 y} / m_{u, 0 x}\right)\end{array}$ \\
\hline$v(x)$ & $\begin{array}{l}\text { along diagonal yield lines } \\
\text { lateral displacements of the slab at the } \\
\text { axis of rotation in the } y \text {-direction }\end{array}$ & $\theta$ & $\begin{array}{l}\text { rotation relative to the horizontal } \\
\text { plane of the triangular slab regions } \\
\text { for the } x \text {-direction }\end{array}$ \\
\hline$w_{0}$ & central vertical deflection & $\theta^{\prime}$ & rotation relative to the horizontal \\
\hline$w_{c r}$ & $\begin{array}{l}\text { central vertical deflection } \\
\text { corresponding to first cracking }\end{array}$ & & $\begin{array}{l}\text { plane of the triangular slab regions } \\
\text { orthogonal to the diagonal yield lines }\end{array}$ \\
\hline
\end{tabular}


parameter describing the effect of transverse cracking in the bond strength

$\mu(y) \quad$ parameter describing the variation of concrete depth with respect to the neutral axis for pure bending $(n=0)$

$\sigma \quad$ generic cross-sectional normal stress

$\tau \quad$ bond stress between concrete and rebar

$\tau_{b} \quad$ average effective bond strength between concrete and rebar

$\tau_{b, m} \quad$ average bond strength considering transverse cracking

$\tau_{b, y} \quad$ average bond strength considering yielding

$\tau_{b, u} \quad$ average bond strength when $\varepsilon_{s, u}$ is reached

$\begin{array}{ll}\varphi & \begin{array}{l}\text { rotation relative to the horizontal } \\ \text { plane of the trapezoidal slab regions } \\ \text { for the } y \text {-direction } \\ \varphi^{\prime}\end{array} \\ & \begin{array}{l}\text { rotation relative to the horizontal } \\ \text { plane of the trapezoidal slab regions } \\ \text { orthogonal to the diagonal yield lines } \\ \chi_{A}, \chi_{B}\end{array} \quad \begin{array}{l}\text { ultimate curvatures } \\ \psi^{\prime}\end{array} \quad \begin{array}{l}\text { parameter defining the yield line } \\ \text { pattern } \\ \phi_{b}\end{array} \quad \begin{array}{l}\text { average diameter of the reinforcing } \\ \text { bars in the } x \text {-direction } \\ \Omega_{y}\end{array} \quad \begin{array}{l}\text { parameter describing the effect of } \\ \text { yielding on the bond strength } \\ \text { slope of the load-deflection curve at } \\ \text { the end of the pre-yielding stage }\end{array}\end{array}$

\section{References}

[1] Park R, "Ultimate strength of rectangular concrete slabs under short-term uniform loading with edges restrained against lateral movement," Proceedings, Institution of Civil Engineers, vol. 28, no. Paper 6705, pp. 125-150, June 1964.

[2] Keenan WA, "Strength and behavior of restrained reinforced concrete slabs under static and dynamic loadings," Technical Report R621, U.S. Naval Civil Engineering Laboratory, Port Hueneme, California, April 1969.

[3] Sawczuk A, "Membrane action in flexure of rectangular plates with restrained edges," Flexural Mechanics of Reinforced Concrete, American Concrete Institute, Special Publication, vol. 12, pp. 347-358, November 1964.

[4] Gouverneur D, Caspeele R, Taerwe L, "Experimental investigation of the load-displacement behaviour under catenary action in a restrained reinforced concrete slab strip," Engineering Structures, vol. 49, no. 4, pp. 1007-1016, April 2013.

[5] Park R, "Tensile membrane behaviour of uniformly loaded rectangular reinforced concrete slabs with fully restrained edges," Magazine of Concrete Research, vol. 16, no. 46, pp. 39-44, March 1964.

[6] Brotchie JF, Holley MJ, "Membrane action in slabs," Cracking, Deflection and Ultimate Load of Concrete Slabs Systems, ACI Special Publication-30, American Concrete Institute, pp. 345-377, 1971.

[7] Sawczuk A, Winnicki L, "Plastic behavior of simply supported reinforced concrete plates at moderately large deflections," International Journal of Solids and Structures, vol. 1, no. 1, pp. 97-111, February 1965.

[8] Wood RH, Plastic and elastic design of slabs and plates with particular reference to reinforced concrete floor slabs, London: Thames and Hudson, 1961.

[9] Taylor R, "A note on a possible basis for a new method of ultimate load design of reinforced concrete slabs," Magazine of Concrete Research, vol. 17, no. 53, pp. 183-186, December 1965.

[10] Kemp KO, "Yield of a square reinforced concrete slab on simple supports, allowing for membrane forces," The Structural Engineer, vol. 45, no. 7, pp. 235-240, July 1967.

[11] Morley CT, "Yield-line theory for reinforced concrete slabs at moderately large deflections," Magazine of Concrete Research, vol. 19, no. 61, pp. 211-222, December 1967. 
[12] Hayes B, "Allowing for membrane action in the plastic analysis of rectangular reinforced concrete slabs," Magazine of Concrete Research, vol. 20, no. 65, pp. 205-212, December 1968.

[13] COST Action TU0601, Robustness of Structures: Final Deliverables and Report, 2011.

[14] Bailey CG, White DS, Moore DB, "The tensile membrane action of unrestrained composite slabs simulated under fire conditions," Engineering Structures, vol. 12, no. 22, pp. 1583-1595, December 2000.

[15] Foster SJ, Bailey CG, Burgess IW, Plank, RJ, "Experimental behaviour of concrete floor slabs at large displacements," Engineering Structures, vol. 26, no. 9, pp. 1231-1247, July 2004.

[16] Bailey CG, Toh WS, "Small-scale concrete slab tests at ambient and elevated temperatures," Engineering Structures, vol. 29, no. 10, pp. 2775-2791, October 2007.

[17] Cashell KA, Elghazouli AY, Izzuddin BA, "Failure assessment of lightly reinforced floor slabs. I: Experimental investigation," Journal of Structural Engineering, vol. 137, no. 9, pp. 977-988, April 2011.

[18] Izzuddin BA, Tao XY, Elghazouli AY, "Realistic modelling of composite and reinforced concrete floor slabs under extreme loading. I: Analytical method," Journal of Structural Engineering, vol. 130, no. 12, pp. 1972-1984, November 2004.

[19] Bailey CG, Toh WS, Chan BM, "Simplified and advanced analysis of membrane action of concrete slabs," ACI Structural Journal, vol. 105, no. 1, pp. 30-40, January 2008.

[20] Bailey CG, Toh WS, "Behaviour of concrete floor slabs at ambient and elevated temperatures," Fire Safety Journal, vol. 42, no. 6-7, pp. 425-436, September-October 2007.

[21] Omer E, Izzuddin BA, Elghazouli AY, "Failure of unrestrained lightly reinforced concrete slabs under fire — Part I: Analytical models,” Engineering Structures, vol. 32, no. 9, pp. 2631-2646, September 2010.

[22] Cashell KA, Elghazouli AY, Izzuddin BA, "Failure assessment of lightly reinforced floor slabs. II: Analytical studies," Journal of Structural Engineering, vol. 137, no. 9, pp. 989-1001, April 2011.

[23] Park R, Gamble WL, Reinforced Concrete Slabs, 2nd Edition ed., New York: John Wiley \& Sons, Inc., 2000.

[24] Johansen KW, Brudlinieteorier, Copenhagen: Jul. Gjellerups Forlag, 1943, p. 191.

[25] International Federation for Structural Concrete (fib), fib Model Code 2010, 1st ed., Lausanne: Ernst\&Sohn, 2013.

[26] Vanderbilt MD, Sozen MA, Siess CP, "Deflection of reinforced concrete floor slabs," Structural research series no. 263, University of Illinois Urbana, Illinois, April 1963.

[27] Timoshenko S, Woinowsky-Krieger S, Theory of plates and shells, 2nd ed., New York City: McGraw-Hill, 1987.

[28] Park R., Gamble W. L., Reinforced Concrete Slabs, 2nd Edition ed., New York: John Wiley \& Sons, Inc., 2000.

[29] Marti P, Baustatik: Grundlagen - Stabtragwerke - Flächentragwerke, Berlin: Ernst \& Sohn, 2012.

[30] Gunay MS, Sucuoglu H, "An equivalent linearization procedure for displacement-based seismic assessment of vulnerable RC buildings," Advances in Earthquake Engineering for Urban Risk Reduction, vol. 66 of the series Nato Science Series: IV: Earth and Environmental Sciences, pp. 63-78, 2005.

[31] Draper NR, Smith H, Applied Regression Analysis, 3rd ed., Michigan: Wiley-Interscience, 1998.

[32] Westgard JO, Basic Method Validation, 3rd ed., W. Q. Corporation, Ed., Chicago: University of Chicago, 2008. 